\title{
Spatial and Temporal Distribution of Rainfall Breaks in Senegal
}

\author{
Bara Ndiaye, Mahamat Adoum Moussa, Malick Wade, Abdoulaye Sy, \\ Abdoulaye Bouya Diop, Aichetou Dia Diop, Bouya Diop, Aboubakary Diakhaby \\ Laboratoire des Sciences de l'Atmosphère et de Océans Matériaux Énergie Dispositifs (LSAOMED), Saint-Louis, Senegal \\ Email: bouya.diop@ugb.edu.sn
}

How to cite this paper: Ndiaye, B., Moussa, M. A., Wade, M., Sy, A., Diop, A. B., Diop, A. D., Diop, B., \& Diakhaby, A. (2021). Spatial and Temporal Distribution of Rainfall Breaks in Senegal. American Journal of Climate Change, 10, 533-560.

https://doi.org/10.4236/ajcc.2021.104027

Received: February 2, 2021

Accepted: December 21, 2021

Published: December 24, 2021

Copyright $\odot 2021$ by author(s) and Scientific Research Publishing Inc. This work is licensed under the Creative Commons Attribution International License (CC BY 4.0).

http://creativecommons.org/licenses/by/4.0/

\begin{abstract}
This study analyzes the spatio-temporal distribution of daily rainfall data from 13 stations in the country of Senegal located in the North-West of Africa. These data, covering the period 1950-2010, are extracted from the database of the Regional Study Center for the Improvement of Drought Adaptation (CERAAS). They allow to calculate, in each station, dry episodes and their sequences and the results reveal a latitudinal variability of class 1 breaks (1 - 3 days) with the highest values recorded in the south. Unlike the class 2 episodes (greater or equal than 15 days), the latitudinal gradient is less pronounced but they are more frequent in the north. For most of the regions studied, a break in the trend towards an increase in dry sequences can be noted, most often at the beginning of the 1970s, which coincides with the start of the great drought of the 1970s decade. For all sites, the frequency of dry episodes of class 1 ( 1 - 3 days) exceeds $70 \%$. The frequency of class 2 of dry episodes (greater or equal than 15 days) decreased from $30 \%$ in $1951-1970$ to $18 \%$ in $1991-2010$ in the region of Thiès; from $25 \%$ in 1951-1970 to $20 \%$ in 1991-2010 in Louga; from $22 \%$ in $1951-1970$ to $18 \%$ in $1991-2010$ in Tamba; $23 \%$ in $1951-1970$ to $15 \%$ in 1991-2010 in Ziguinchor; $25 \%$ in 1951-1970 to $16 \%$ in 1991-2010 in Kolda; $22 \%$ in $1951-1970$ to $18 \%$ in $1991-2010$ in Diourbel and finally $20 \%$ in 1951-1970 to 17\% in 1991-2010 in Fatick. Over the whole period of study, the spatial distribution of the number of dry periods in class 1 is higher in the South than in the Center and in the North of Senegal. For class 2 breaks, the latitudinal gradient is less pronounced and the minimum number of dry periods in this class is recorded in the south, especially in Ziguinchor. However, the maximum is observed in the Center. In the Northern region (Saint-Louis), classes 3 and 4 are much more frequent. This spatial variability of rainfall breaks is clearly associated with the rainfall gradient between the North and the South. The temporal evolution of the numbers of each class intrinsically follows the evolution of the ITCZ.
\end{abstract}




\section{Keywords}

Rainfall, Rainfall Breaks, Great Drought, Senegal, Consecutive Dry Days

\section{Introduction}

Senegal is currently facing a very strong degradation of its agricultural production capacity. With a population of about 16.209 .125 habitants in 2019, it will have to feed about 19.390.727 habitants in the horizon of 2025 according to the Senegalese National Agency of Statistics and Demography (ANSD). According to an essentially extensive agriculture and a strong climate variability characterizing the area, the food supply of these populations represents an even more difficult challenge to overcome. The increasing frequency of extreme events such as floods, prolonged rainy breaks, droughts (International Panel on Climate Change; IPCC, 2019), but also the delay in the start and the short duration of the rainy season will increase the vulnerability of agricultural production systems. To decrease consequences of this vulnerability on local populations, the Senegalese scientific community must double its efforts to improve the understanding and prediction of climate variability and change in the country. It is in this context that some projects at the level of the Sahelian sub-region have emerged, such as AMMA (Multidisciplinary Analysis of the African Monsoon) (Redelsperger et al., 2006; Lebel et al., 2010), ESCAPE (Environmental and Social Changes in Africa: Past, present and future) (Sultan et al., 2011), CORDEX (Coordinated Regional Downscalling Experiments, http://wcrp.ipsl.jussieu.fr), etc. The originality of these projects lies in the scope of the field measurement campaigns, their multidisciplinary and multilateral character in order to better identify the mechanisms and complexity of the monsoon system at different time and space scales and in consequence improve our knowledge.

In Senegal, there are hardly studies that have focused on updating the state of the art on the spatio-temporal distribution of rainy breaks, i.e. characterizing the temporal and multisite distribution of rainy days in this region of the Sahel. However, this is crucial given the increased spatio-temporal variability of rainfall in this region of the Sahel but also the uncertainty of climate projections, especially those of rainfall. Nevertheless, some authors have described breaks in rainfall at the sub-regional level (Garcia \& Martin-Vide, 1993; Sané et al., 2008) and in East Africa (Segele \& Lamb, 2005). Salack et al. (2012) showed that extreme breaks were more frequent at the beginning and end of the season. They showed that breaks longer than 15 days (May-June-July) and 8 - 14 days (August-September) are of low frequency of occurrence and correlated with annual rainfall deficits. However, since the drought of the 1970s in West Africa, these extreme breaks have become more and more frequent even in mid-season (Bichet \& Diedhiou, 2018; Porkka et al., 2021). Sivakumar (1992) described breaks at different thresholds of daily rainfall $(1 ; 5 ; 20$ and $25 \mathrm{~mm} /$ day $)$ during the 
cropping season from the date of sowing which is defined as the date after 1 May, when the accumulated rainfall on at least three consecutive days is $20 \mathrm{~mm}$ and no dry period within the following 30 days exceeds 7 days. However, in a context of climate change these sowing dates are highly variable and the growing seasons have become shorter and shorter especially in Senegal. Sané et al. (2008), to characterize the rainy season through rainfall breaks, used only two stations in southern Senegal (Kolda and Vélingara). However, these two stations are located in a humid zone ( $>800 \mathrm{~mm} /$ year) whereas the agro-climatic risks associated with rainfall breaks are more important in arid and semi-arid regions of the Sahel as shown by Barron et al. (2003). Fodé \& Adamou (1996) studied dry sequence analysis in Niger by trying to fit empirical (observed) dry sequence distributions using MARKOV chain models. It appeared that the second-order MARKOV chain gives a better fit to the empirical probability distribution of occurrence of dry sequences, the higher the frequency of rainfall and the length of the dataset is limited to the last rainy day of the season, the better the match. In the Sahel, the control of rainfall distribution and variability, which is also an indirect way of characterizing the distribution and variability of rainfall breaks, remains a challenge for the scientific community as well as for the populations and all development actors. Indeed, in its sixth Assessment Report, the Intergovernmental Panel on Climate Change (IPCC, 2016), considers that climate projections in the 21 st century remain subject to uncertainties. One of the main causes of these uncertainties is the lack of a perfect mastery of the physical processes and mechanisms that drive rainfall variability in West Africa. At the level of the population of the region, adaptation to rainfall variability is a vital issue. In addition, the population of the region lives mainly from rain-fed agriculture or extensive livestock depending not only on seasonal rainfall accumulation but also on intra-seasonal rainfall variability.

The recurrent droughts and the decline in agricultural productivity over the last two decades in West Africa highlight the need to better understand the duration of dry periods and especially their frequency. In Senegal, agriculture is defined as a driving sector of the economy in the program Plan Sénégal Émergent (PSE) which serves as a reference framework for public policies over the period 2014-2035. The program Programme d'Accélération de la Cadence de l'Agriculture Sénégalaise (PRACAS) represent the agricultural component of the PSE program. The agricultural sub-sector is characterized in 2016 by a counter-performance of certain agricultural varieties such as millet, groundnuts and maize in connection with the rainfall deficit (ANSD, 2019). It is an essentially extensive agriculture subject to many constraints, among which we can cite the following:

- the lack of rice fields with water control mechanisms;

- climate variability and change;

- insufficient certified seed;

- soils that are generally shallow, with surface crusting that promotes runoff, low water retention capacity and low organic matter content. They are subject to strong water and wind erosion in the Sahelian zone and are showing 
signs of exhaustion.

This work aims to contribute to the improvement of our understanding of the spatial and temporal distribution of rainfall breaks in Senegal. It seeks to detect rainfall breaks for each selected station in the country of Senegal but also to characterize them in terms of frequency, classification and duration. Moreover, their relationships with rainfall variability before and after the drought of the 1970s in the Sahel are examined.

\section{Data and Methods}

\subsection{Study Area}

Senegal is located at the extreme west of West Africa between latitudes $12^{\circ} 30 \mathrm{~N}$ $16^{\circ} 30 \mathrm{~N}$ and longitudes $11^{\circ} 30 \mathrm{~W}-17^{\circ} 30 \mathrm{~W}$ and covers about $197.000 \mathrm{~km}^{2}$. The topography of the country is free of steep terrain. Only a small part of the relief, on the south-eastern border with Guinea, is relatively high with altitudes greater than $200 \mathrm{~m}$ above the sea level. Trees and shrubby steppe dominate the north, wooded savannah predominates in the center of the country while dense savannah and forest are increasingly found towards the south (Moron et al., 2006). Apart from large and mesoscale factors, local atmospheric circulation is particularly influenced by the proximity to the North Atlantic Ocean.

In Senegal, cumulative rainfall follows a north-south gradient and southern areas receive rainfall at the beginning and end of the monsoon due to its north-south migration. The rainy season lasts longer in the southern than in the northern and central zones of the country. Analysis of precipitation records over the stations shows a clear downward trend in cumulative rainfall throughout the country during the period 1951-2010 (not shown). This situation corroborates the rainfall deficit observed in the country since the late 1960s (Sané, 2003). Four different rainfall zones can be identified in Senegal based on cumulative rainfall characteristics. There is the northern zone (NZ) which is the part of the country where the average annual cumulative rainfall does not exceed $400 \mathrm{~mm}$ (Louga and St. Louis). In this zone, rain-fed agriculture is technically difficult, if not impossible, each year because of recurrent rainfall deficits. The central north zone $(\mathrm{CN})$ has an average cumulative annual rainfall between 400 - $600 \mathrm{~mm}$ (Dakar, Thies, Diourbel), and the central south zone (CS) has an average cumulative annual rainfall of between $600-800 \mathrm{~mm}$ (Kaffrine, Kaolack, Tamba). These two zones encompass the groundnut basin and have fairly diversified agricultural potential. Finally, the southern zone (SZ) has an average cumulative rainfall of more than $800 \mathrm{~mm}$. It has a fairly secure agricultural system that uses long-cycle millet varieties, sorghum, maize, cotton and rice.

\subsection{Data}

In the framework of this work, it was necessary to gather rainfall data from several stations in Senegal (Figure 1) in order to carry out this research. These data are 


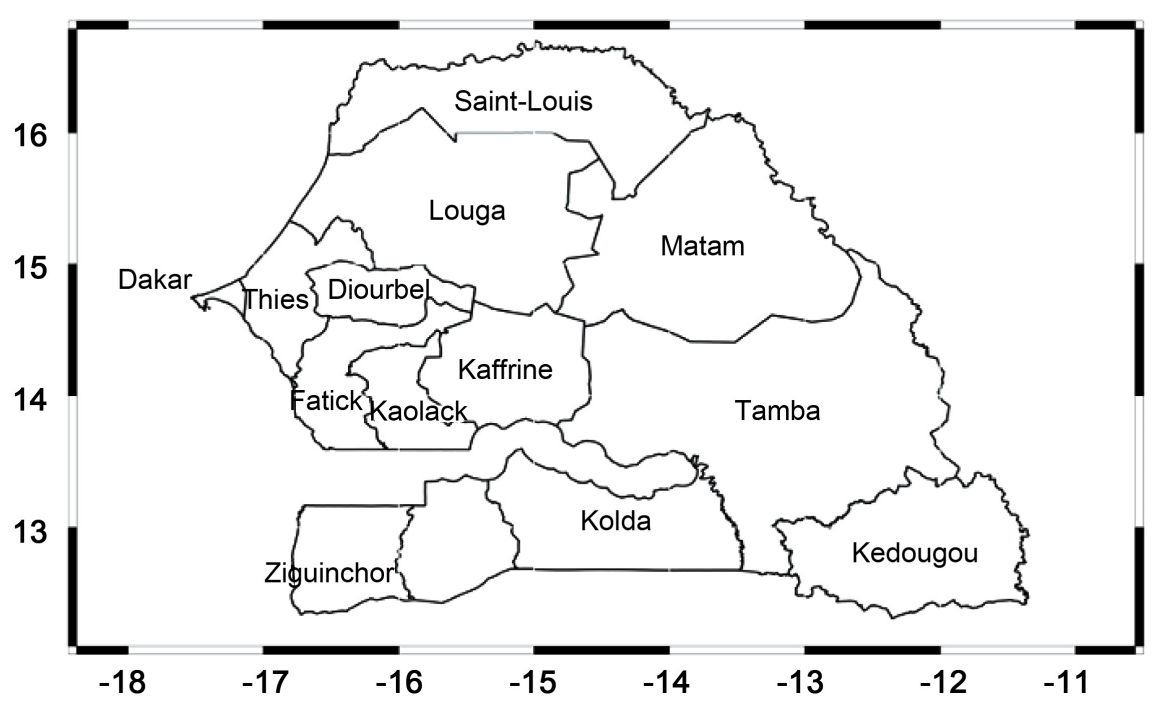

Figure 1. Location of the different areas studied.

extracted from the database of the Centre d'Études Régional pour l'Amélioration de l'Adaptation à la Sécheresse (CERAAS). They come from various observation networks including that of the National Meteorological Agency of Senegal (ANAMS), currently the National Agency of Civil Aviation and Meteorology (ANACIM) and that set up by the Senegalese Institute of Agricultural Research (ISRA) within the framework of national agro-sylvo-pastoral monitoring. It is a daily database of about hundred measurement points spread throughout the national territory. It is made up of synoptic, climatological and rainfall stations maintained by the Departmental Rural Development Services (SDDR).

\subsection{Methodology}

The main agro-climatic parameters are the start date, the length of the season and eventually the end of the season. Their knowledge is essential in several areas such as fishing, livestock and especially agriculture where breaks of more than 20 days seriously threaten the fields and the grass that serves as food for livestock.

\subsubsection{Start and End Dates of the Season}

There are several criteria for determining the start date, but the one used to determine these parameters is that of Sivakumar (1992) because of its simplicity of implementation and is the most widely used in the Sahelian zone.

- The start date of the season according to Sivakumar (1992) corresponds to the date $\mathrm{X}$ on which a quantity of $20 \mathrm{~mm}$ of rain has been collected in three (3) consecutive days after the first of May without a dry period of more than 7 days within the following 30 days.

- The end date of season $\mathrm{Y}$ is the day when, after 1 September, there are no more rains for two decades (20 days).

- The length of the season is obtained simply by taking the difference between Y-X. 


\subsubsection{Dry Sequences}

Notion of drought: Drought is defined as a lack of water availability in relation to a situation considered normal for a given period and a given region (Benzerti \& Habaieb, 2001). There are four types of droughts according to areas of application:

- Meteorological drought: reduction, poor distribution, or absence of rainfall in a given region over a given period of time (Wilhite \& Glantz, 1985).

- Agronomic drought: a situation where soil moisture and water reserves become insufficient to meet crop needs in a given area (Wilhite \& Glantz, 1985).

- Hydrological drought: the deviation of surface and groundwater supply from a normal supply over a given period of time (Wilhite \& Glantz, 1985).

Depending on the context of this work, meteorological drought is more appropriate for our study. Given that drought is a decrease in water availability for a particular time and over a particular region, the notion of drought is relative (Benzerti \& Habaieb, 2001). It is on the basis of this assertion that our study focused on the persistence of drought on an annual scale. The most plausible definition of a rainfall pause is a day without any rainfall record, but meteorologists have set a threshold of $0.1 \mathrm{~mm} /$ day to characterize a rainy day. In order to take into account the errors due to the measurements of the instruments and those rainfall measuring in the stations, a threshold of $1 \mathrm{~mm}$ /day was chosen in our study. Any day with a rainfall value below this threshold is considered as a dry day and a day with a value above this threshold is considered as a rainy day. Thus, two or more consecutive days without rainfall are called dry sequences or dry pockets. Given the fact that there is no official indicator of drought, we have made a representation of the annual rainfall of the different stations, simultaneously with a graph that will represent the average annual rainfall of the whole series and of each site. This allowed us to illustrate the dry years which are the years whose value of the rainfall sum of the whole year is below the curve of the average, and logically the wet years those which will be above.

Under the climate of Senegal, the rainy season (June to October) in our case is characterized by dry and rainy sequences. The numbers of dry sequences during the rainy season and their interannual variability is of capital interest not only to farmers but also to all other rain-dependent domains. The occurrence of dry episodes at certain key phases of the rainy season has adverse consequences on crop development, which may prevent the plant from completing its full vegetative cycle. Knowledge of the variability of dry events in the rainy season in Senegal is of vital importance especially for the prevention of famines and food crises. Our analysis covers the entire period from 1950 to 2010. The breaks have been classified according to their duration. In fact, the majority of the rainy breaks between 1 and 3 days are in class 1, those between 4 and 6 days in class 2 , those between 7 and 9 days in class 3 and finally those over 9 days in class 4 . This period was marked by a great irregularity of episodes of dry days. 


\section{Results}

\subsection{Interannual Variability of Dry Sequences from 1950 to 2010}

The Dakar region recorded an average annual duration of dry episodes of 6.2 days between 1950 and 2010. The interannual variability of the evolution of the number of rainy breaks from 1950 to 2010 shows a substantial downward trend in the number of dry episodes in classes 1 and 2 (Figure 2). The period 1977-1983 records the lowest number of dry episodes in class 1 and the period 1965-1975 that has the lowest number in class 2 . For class 1 , the highest numbers are obtained in 1954 and 2004. Classes 3 and 4 are more intense during the period 1968-1986 coinciding with the period of drought in the Sahel. The maximum rainfall pause recorded in this region from 1950 to 2010 was obtained during 1983 and lasted more than 45 days (Figure 3).
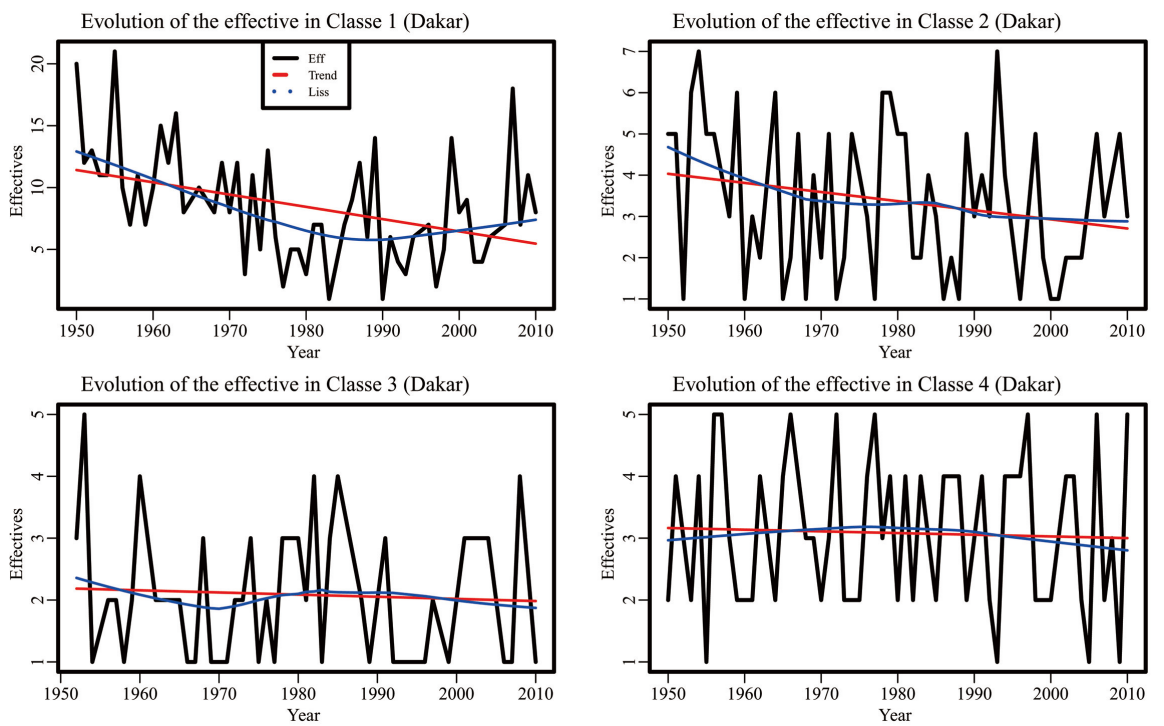

Figure 2. Interannual variability of the percentage of dry episodes in Dakar.
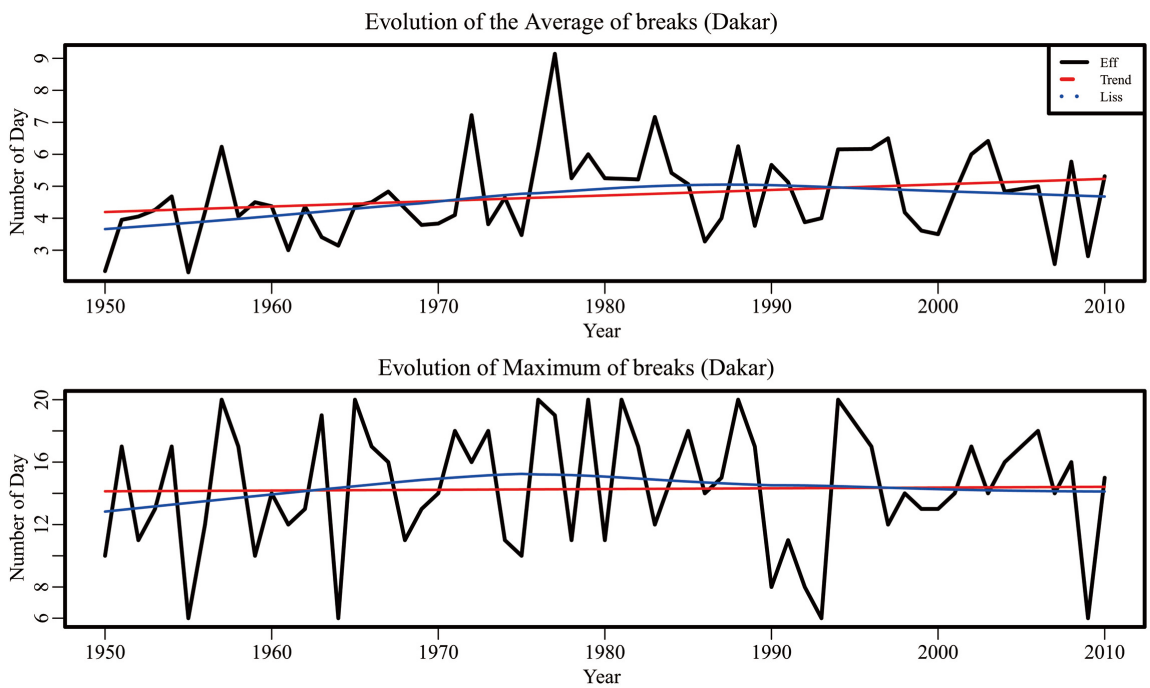

Figure 3. Interannual variability of the average and maxima of dry episodes in Dakar. 
The interannual analysis of dry episodes in the Thies region shows that the maximum rainfall breaks during the whole period 1950-2010 lasted about 42 days and is recorded during the year 1967 (Figure 4). In this region the average duration of dry episodes is about 6 days during the period 1950-2010 (Figure 5). A decreasing trend in the number of dry episodes of class 1 can be noted, contrary to the increasing trend in the number of dry episodes of class 2 . The period 1971-1995 is marked by a decrease in the occurrence of class 3 and 4 breaks but it is the period that records the most extreme dry episodes of these classes in 1973 and 1980 for class 3 and 4 respectively.

In the Kaffrine region, the number of class1 breaks, in the 1950-1965 and 2000-2010 periods, is higher than in the other years of the period 1950-2010 (Figure 6). The average duration of dry episodes in this region is about 5 days
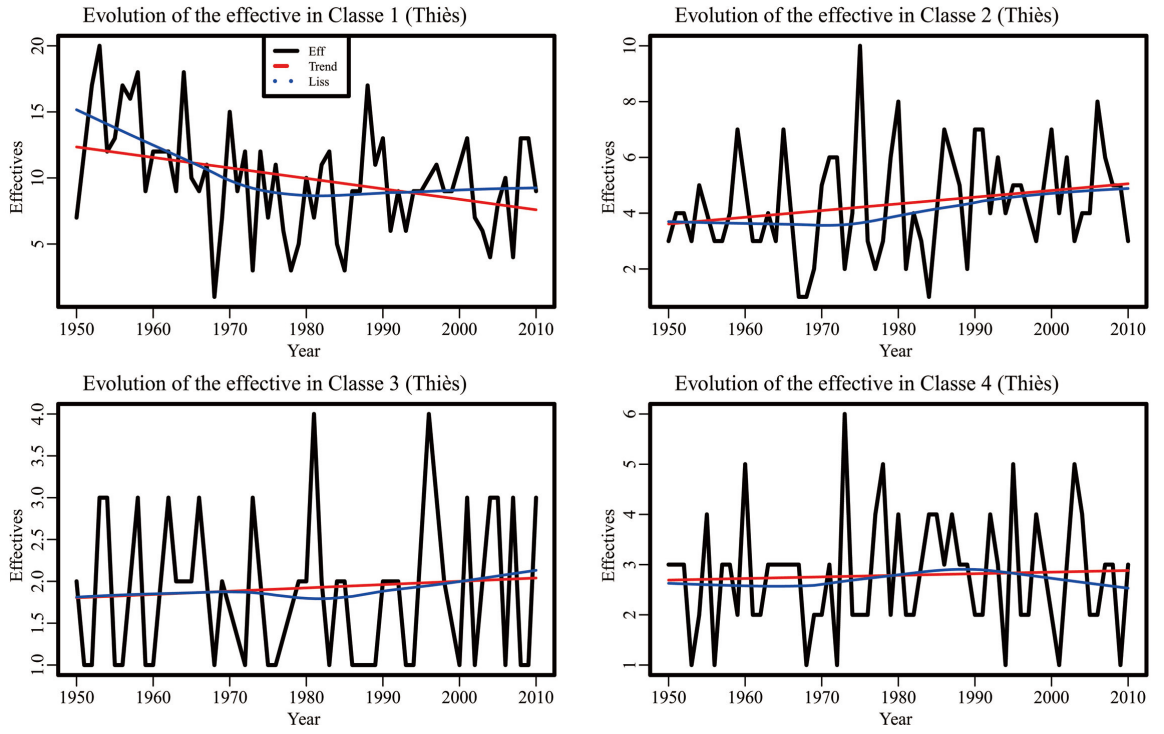

Figure 4. Interannual variability of the percentage of dry episodes in Thiès.
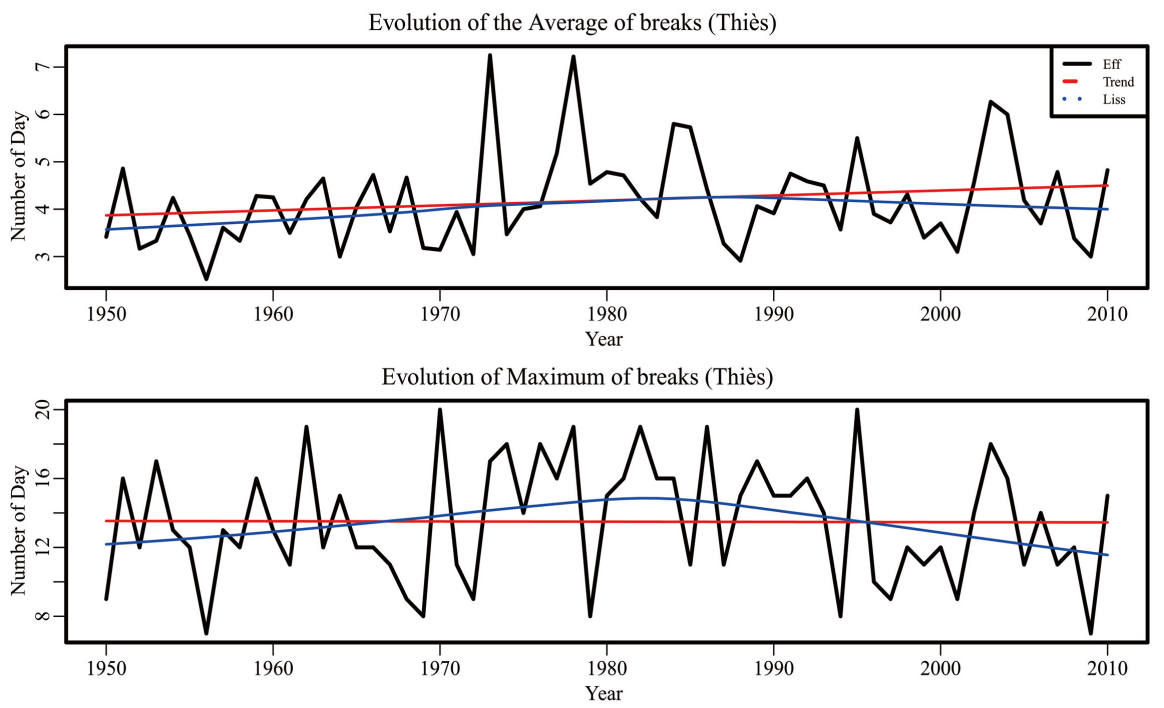

Figure 5. Interannual variability of the average and maxima of dry episodes in Thiès. 

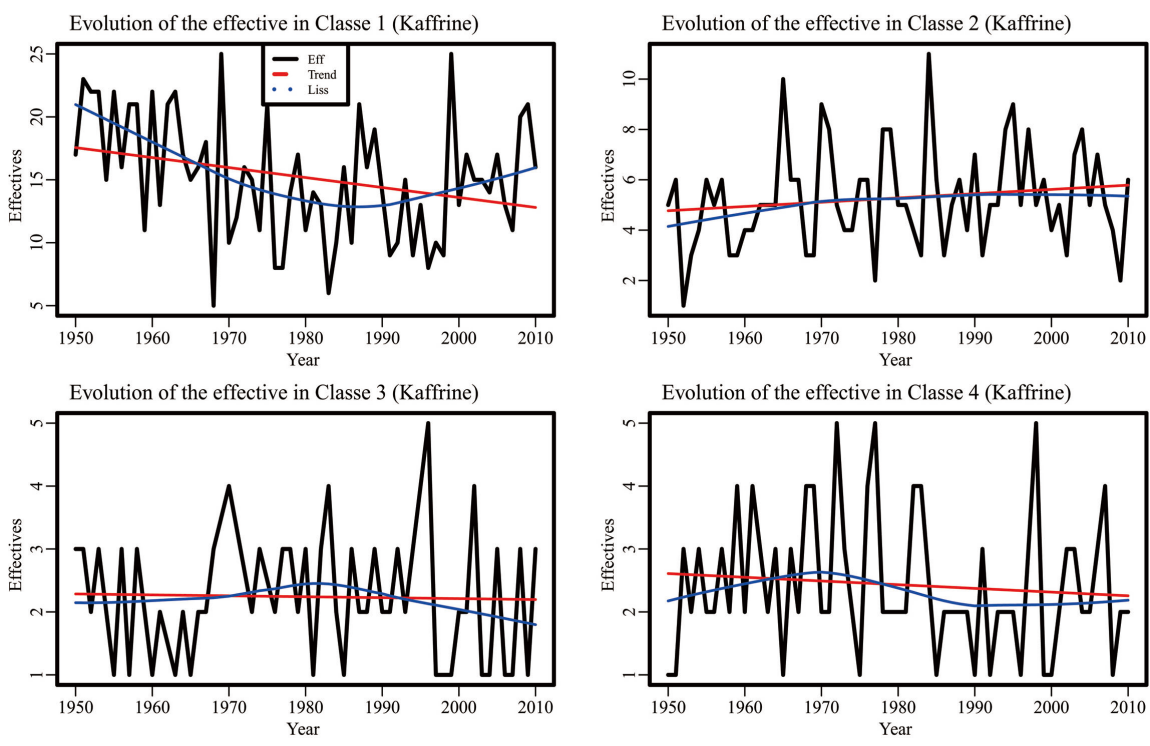

Figure 6. Interannual variability of the percentage of dry episodes in Kaffrine.

and the maximum break recorded over the entire study period (1950-2010) was about 31 days and this was in the year 1978 (Figure 7). The number of breaks in the class 2 in the period 1950-1959 is particularly lower than in the rest of the study period. The frequency of occurrence of breaks in this class has been on an upward trend since 1971, in contrast to that of class 1, which has been decreasing overall. Dry episodes in classes 3 and 4 have a low frequency of occurrence compared to that of classes 1 and 2 and in this region, they were in the majority during the period 1974-1995, especially those in class 3 (Figure 7).

The highest numbers of dry episodes of class 1 are recorded during 1952, 1999 and 2009 in the Kaolack region and the lowest number is obtained in 1983. They increased during the first two decades of the period 1950-2010 before decreasing until 1977. These episodes are slightly decreasing in a global view (Figure 8). In this region the maximum break (duration about 30 days) is obtained in 1961 but the average duration of breaks in this region is 5.2 days (Figure 9). For class 3 breaks the highest numbers are obtained during the periods 1995-1998, 1968, 1950 and 2010 and for class 4 they are recorded during 1969-1980. The dry episodes of this last class have been increasing since 1998 in this region (Figure 8).

Overall, in the Kedougou region, the number of dry episodes in class 1 is decreasing, while those in class 2 and class 4 (despite their low frequency of occurrence) are increasing (Figure 10). The period 1950-1969 is characterized by a very high number of dry episodes of class 1 and quite significant over the period 1995-2010. On the other hand, the period 1970-1998 is characterized by a slightly low number of these episodes (Figure 9). The average duration of breaks in this region is 4.7 days and the maximum break (duration of 25 days) is recorded in 1967 (Figure 11). The frequency of breaks in the class 2 is important during the last 15 years of the period 1950-2010. The extreme breaks in this class are obtained in 1971 and 1975. For the dry episodes of class 3 their numbers are 

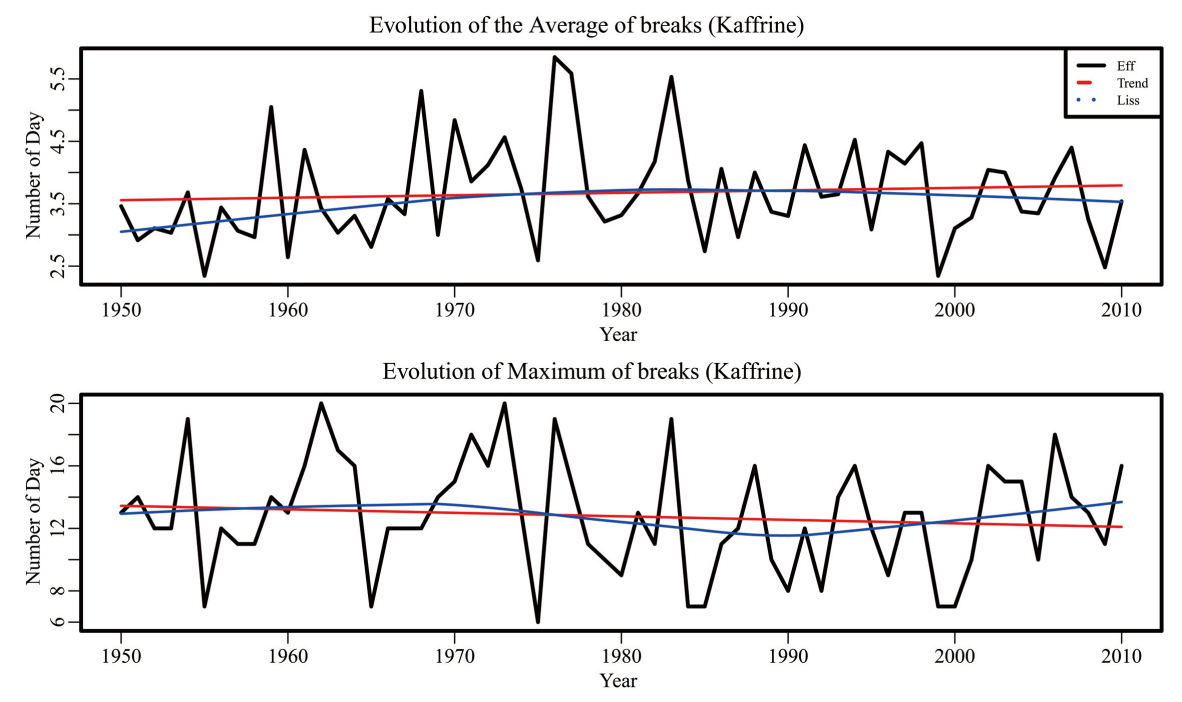

Figure 7. Interannual variability of the average and maxima of dry episodes in Kaffrine.
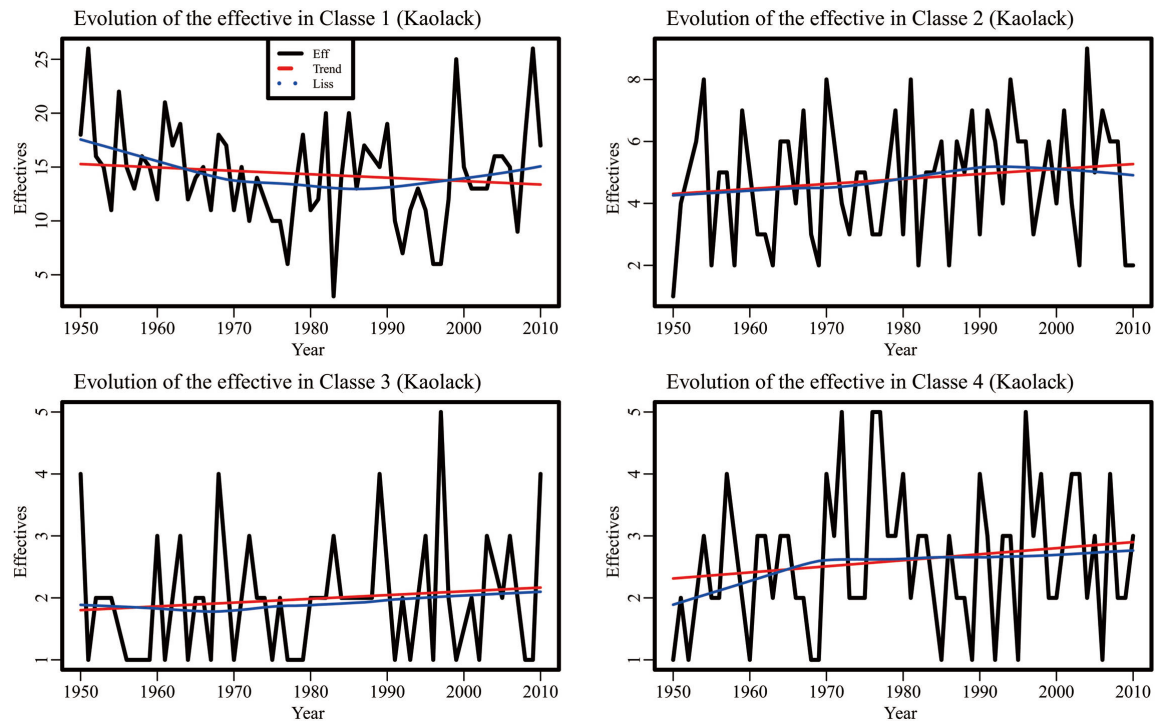

Figure 8. Interannual variability of the percentage of dry episodes in Kaolack.
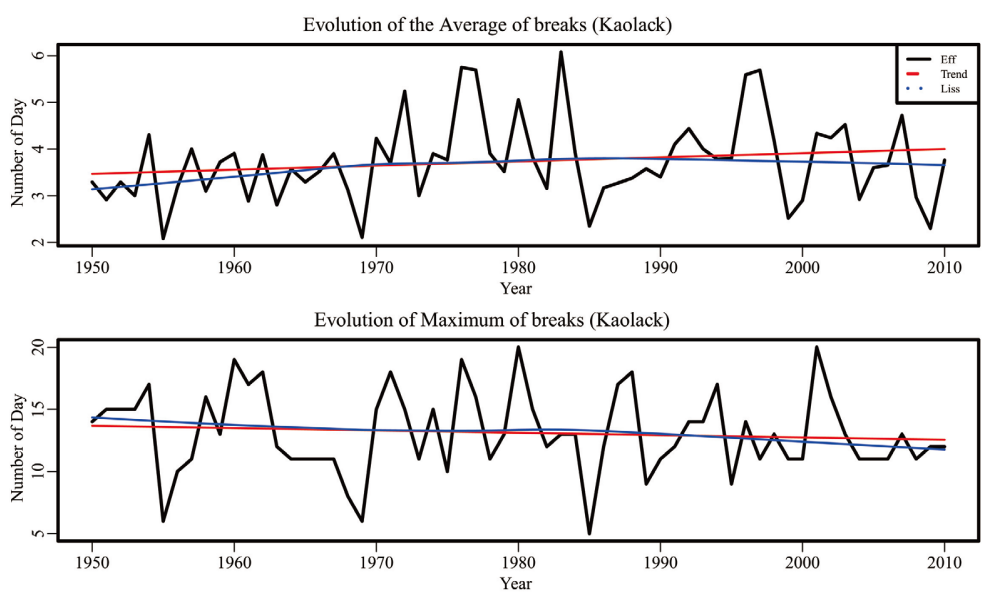

Figure 9. Interannual variability of the average and maxima of dry episodes in Kaolack. 

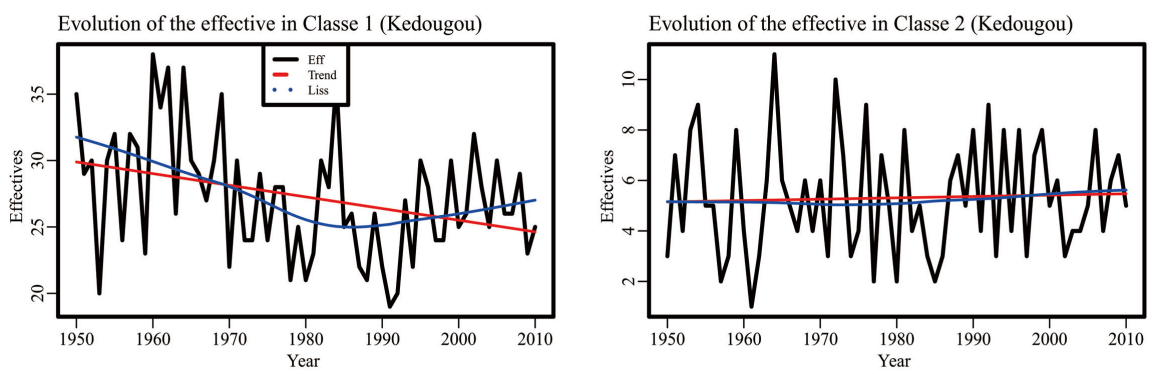

Evolution of the effective in Classe 3 (Kedougou)
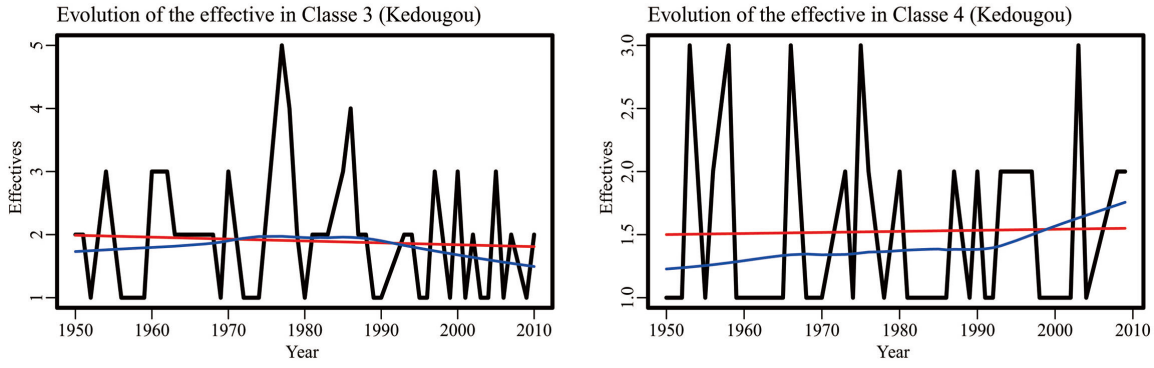

Figure 10. Interannual variability of the percentage of dry episodes in Kedougou.
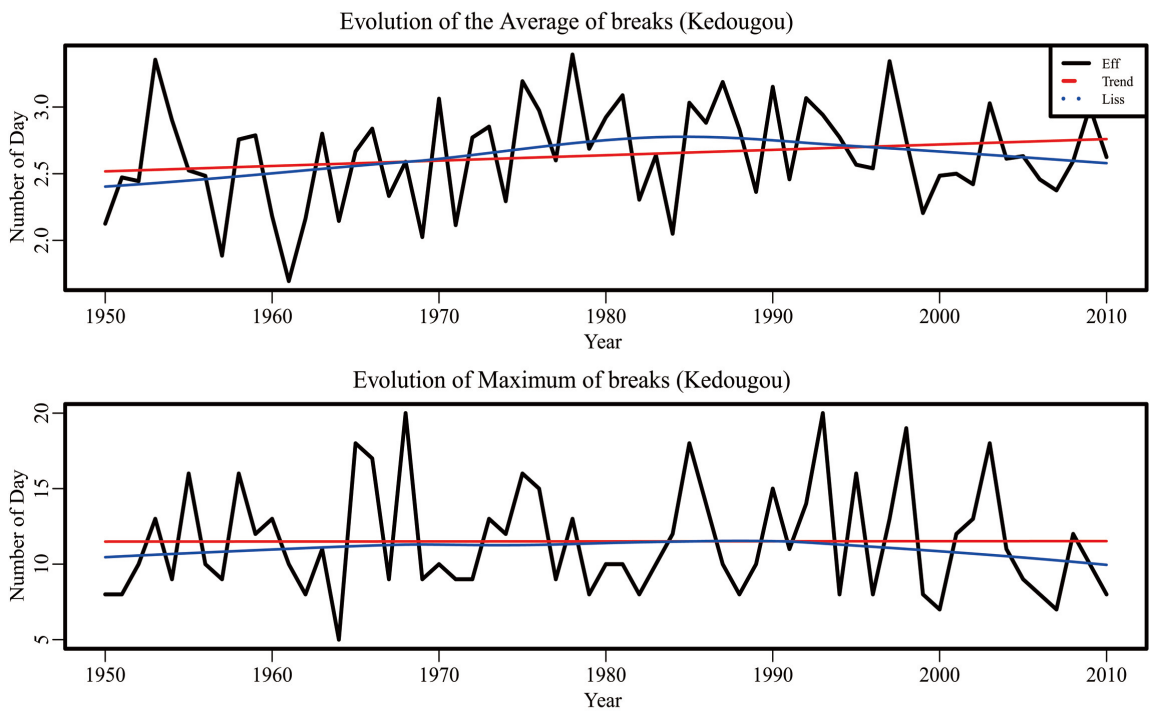

Figure 11. Interannual variability of the average and maxima of dry episodes in Kedougou.

below 3 over the whole period (1950-2010) with the exception of the years 1978 and 1987 (Figure 10).

In the region of Diourbel, the number of rainfalls breaks in class 1 is in a strong decrease and those in class 2 are in a very slight increase. There are two maximum breaks of about 39 days duration throughout the 1950-2010 season, they occurred during the years 1964 and 1980 (Figure 12). The average duration of dry spells in this region is about 5.9 days. During the period 1950 to 1963, the number of class 3 breaks did not exceed 3, while during the last two decades of the period 1950-2010 they reached a number of 5 while for class 2 breaks the highest number was recorded in 1984 (Figure 13).

In the Saint-Louis region, the tendency of the number of rainfalls breaks in 

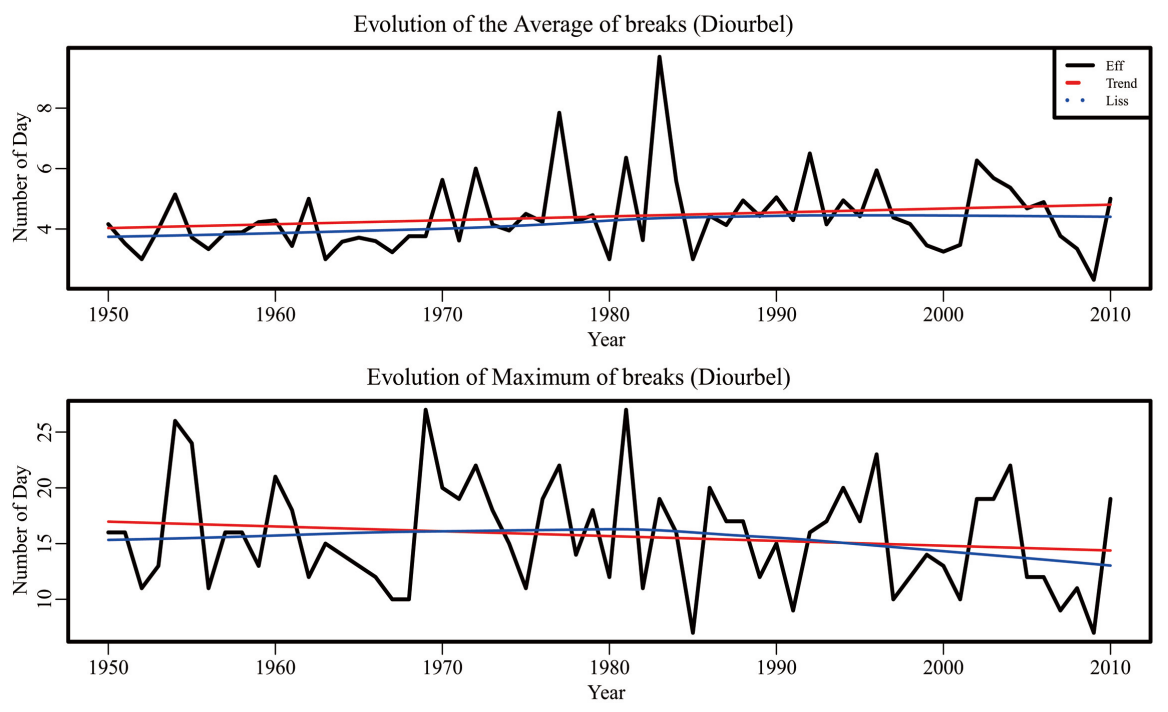

Figure 12. Interannual variability of the average and maxima of dry episodes in Diourbel.
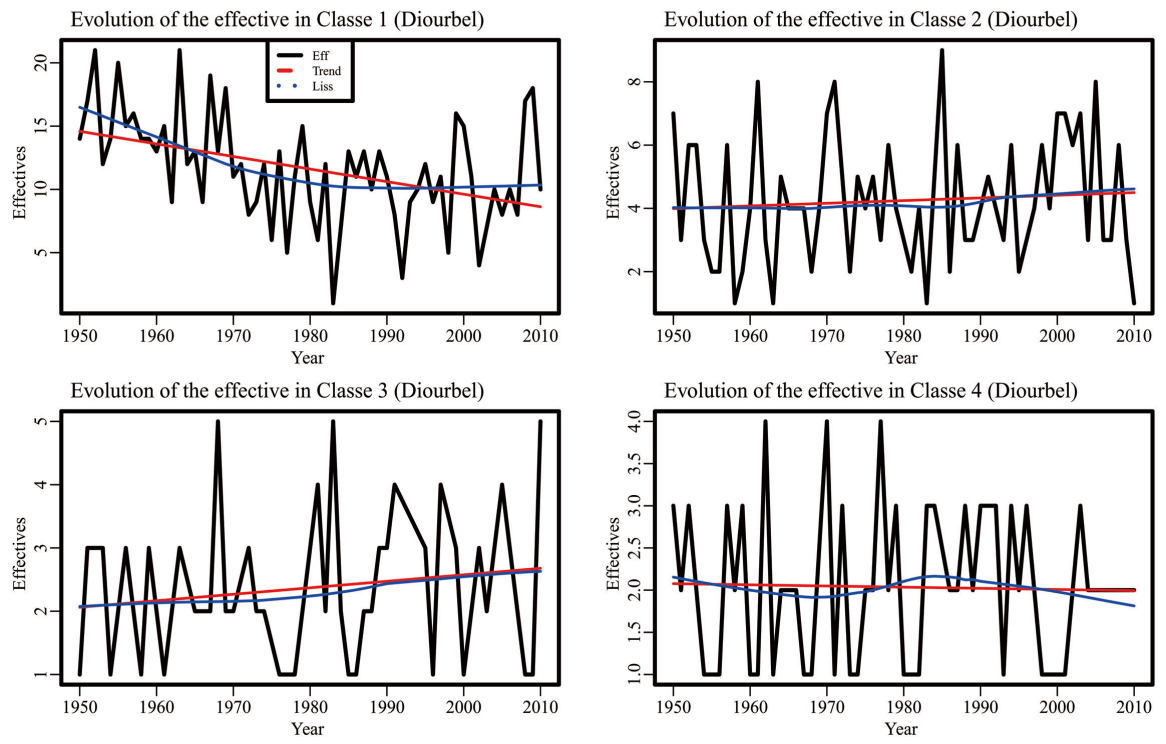

Figure 13. Interannual variability of the percentage of dry episodes in Diourbel.

classes 1 and 2 is generally decreasing, while class 3 is increasing (Figure 14). We can see that the period 1971-1995 displays the lowest value in class 1 compared to the rest of the period. The average duration of rain breaks in this region is about 7.5 days with the maximum break recorded in 1987 and lasted more than 40 days (Figure 15). The last decade, with the exception of 2009, has been marked by a relatively high number of breaks in the class 3 compared to other years.

In the Louga region, Dry episodes of class 1 are strongly decreasing in this region with the lowest numbers recorded during the period 1970-1980 and the highest during the first decade (Figure 16). For class 2, the duration 1971-1995 has the lowest number of days, but for this same class, the last decade is the highest. It can be seen that the breaks in class 4 are on an upward trend with 


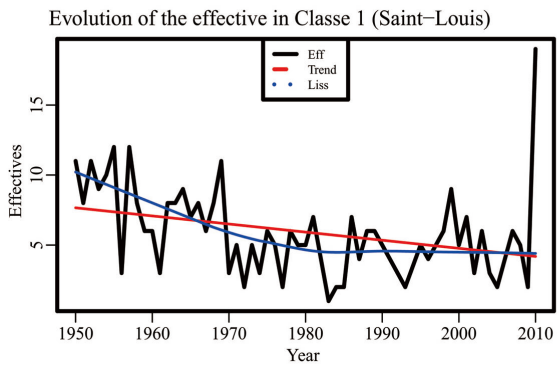

Evolution of the effective in Classe 3 (Saint-Louis)

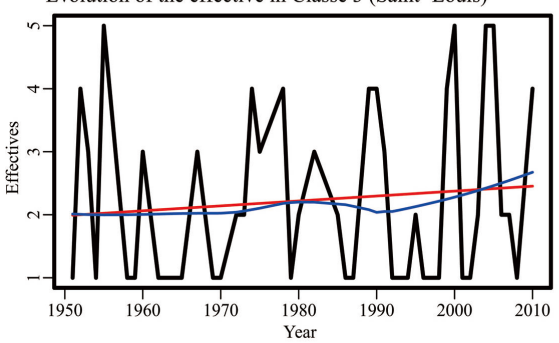

Evolution of the effective in Classe 2 (Saint-Louis)

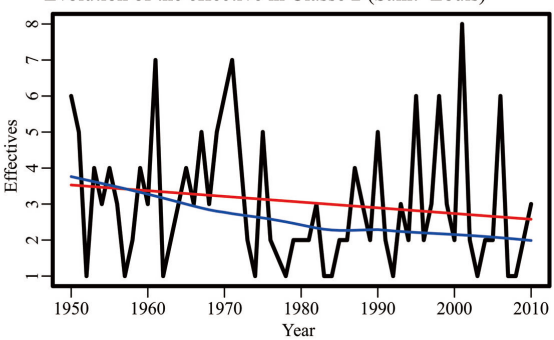

Evolution of the effective in Classe 4 (Saint-Louis)

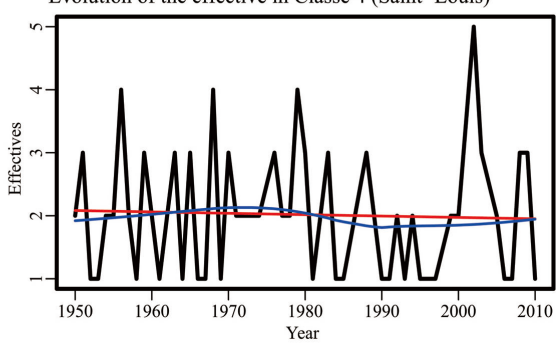

Figure 14. Interannual variability of the percentage of dry episodes in Saint-Louis.
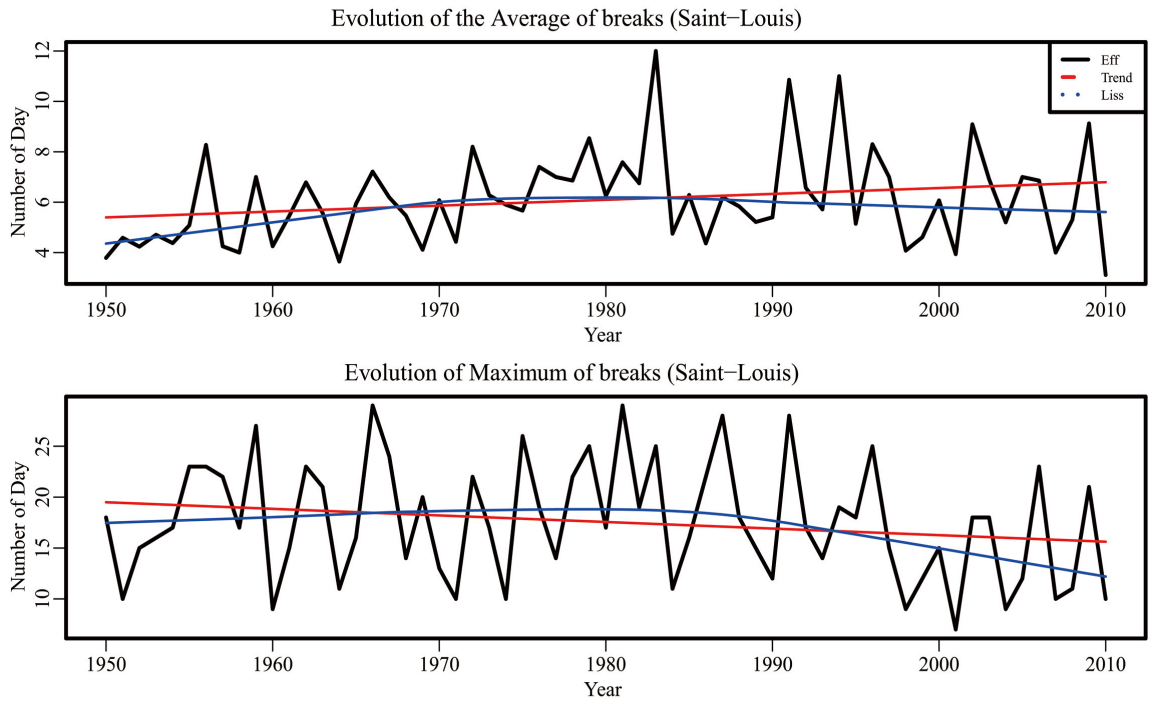

Figure 15. Interannual variability of the average and maxima of dry episodes in SaintLouis.

peaks recorded in 1976 and 2003 (Figure 16). The average duration of dry episodes is 7 days with the maximum dry episode obtained in 1950 with a duration of almost 50 days (Figure 17).

In the Tamba region, it was the year 1999 when a highest number (30) of dry episodes were recorded, followed by the 1955 season (about 28) of class 1 . These episodes have higher numbers during the first decade of the period 1950-2010 (Figure 18). The maximum dry episode recorded during this period is 34 days in 1968 but the average duration of rain breaks is 4.8 days (Figure 19). For the class 2 the period 1970-1986 comes first followed by the last decade of the period 1950-2010. Overall, dry episodes for classes 3 and 4 are increasing (Figure 18).

In the Ziguinchor region, the average duration of dry spells from 1950 to 2010 

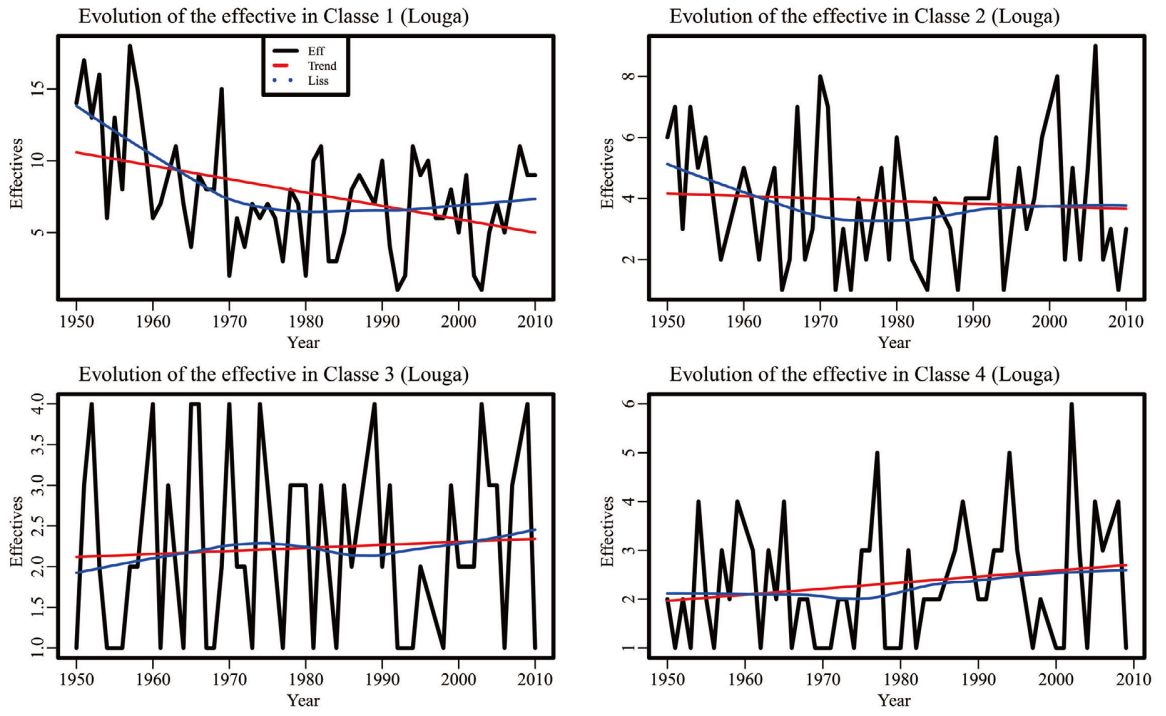

Figure 16. Interannual variability of the percentage of dry episodes in Louga.

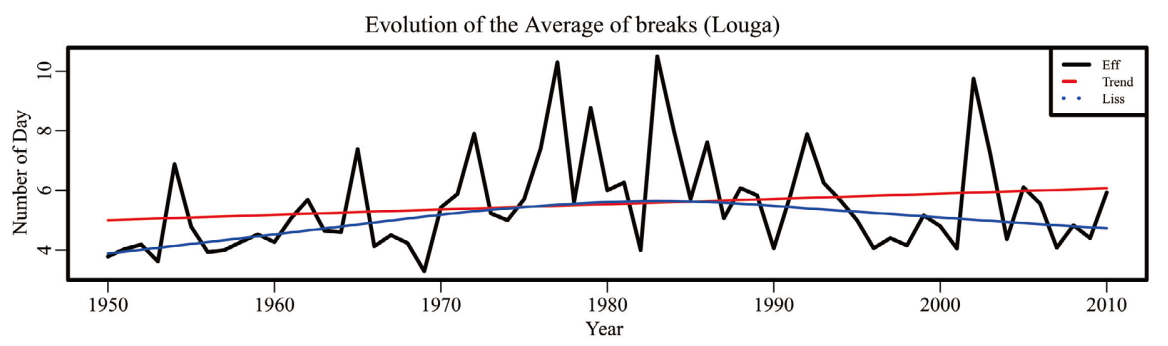

Evolution of Maximum of breaks (Louga)

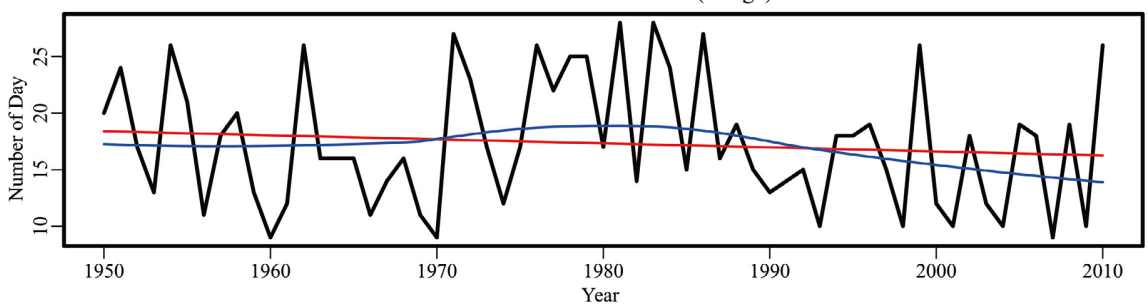

Figure 17. Interannual variability of the average and maxima of dry episodes in Louga.

is 4 days. The two most extreme breaks were recorded in 1953 and 1995 and lasted about 25 days (Figure 20). Class 1 breaks are more frequent over the study period during the first decade and the lowest numbers of this class were recorded during the 1967-1970 period. For class 2 it can be seen that the two highest peaks in the entire period 1950-2010 were obtained during the period 1968-1980. This class is growing overall over the study period. In contrast to class 2 , class 3 is in decreasing and episodes of class 4 have a very low frequency of occurrence (maximum 2) in this region (Figure 21).

The analysis of the dry sequences of the different stations shows a decrease in dry episodes of class $1-3$ from south to north with Kédougou having the largest number of this class followed by the Ziguinchor area. The results also show a hierarchy (decrease) in the number of dry sequences for each region as their duration increases, with Tamba recording the highest number of dry sequences of 

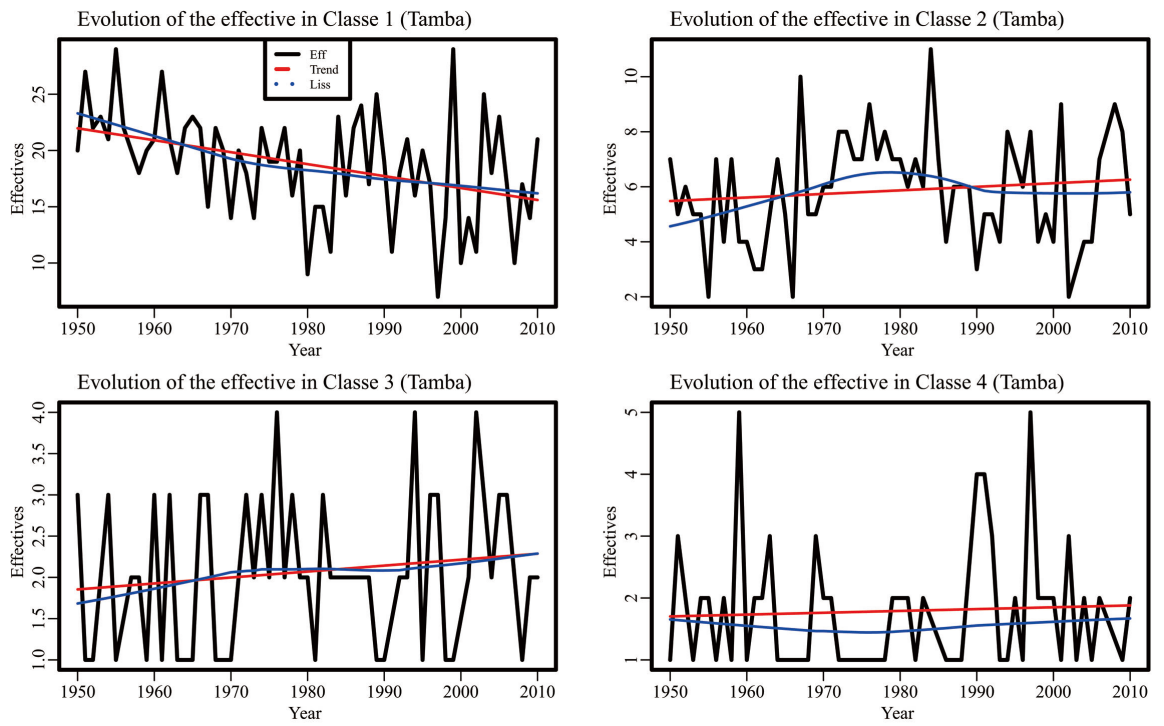

Figure 18. Interannual variability of the percentage of dry episodes in Tambacounda.
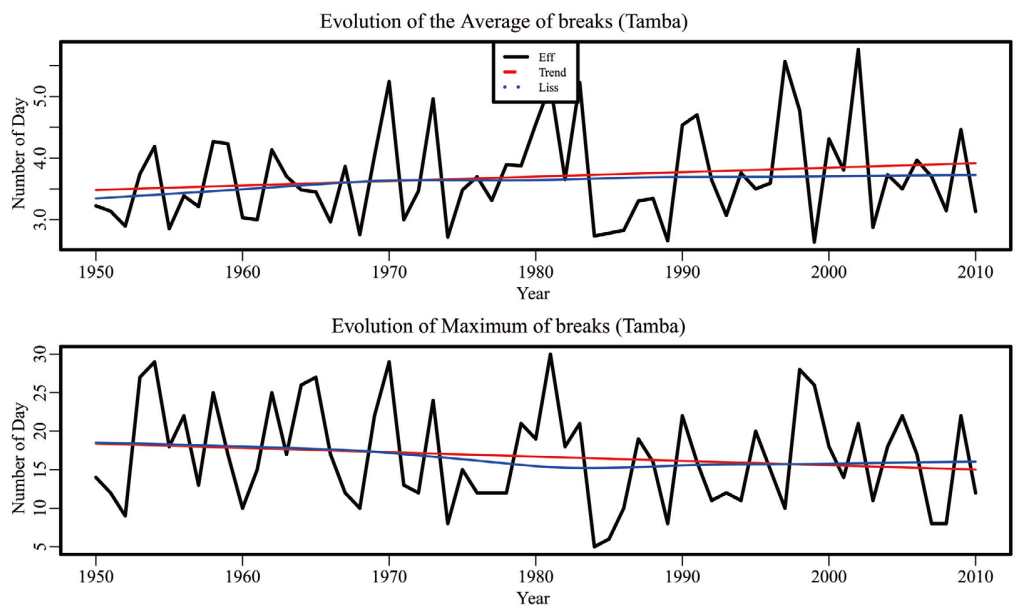

Figure 19. Interannual variability of the average and maxima of dry episodes in Tambacounda.
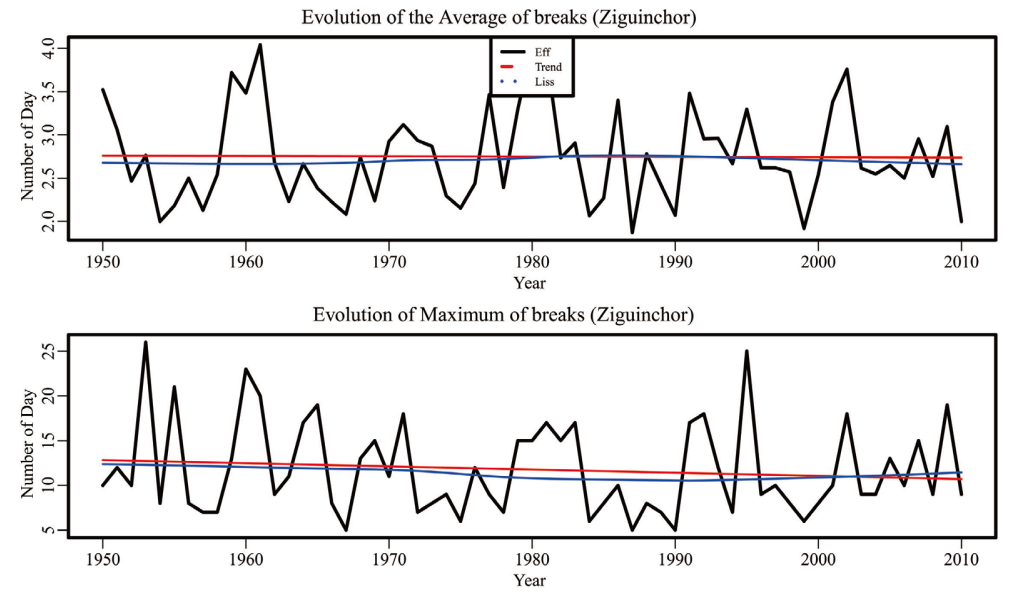

Figure 20. Interannual variability of the average and maxima of dry episodes in Ziguinchor. 


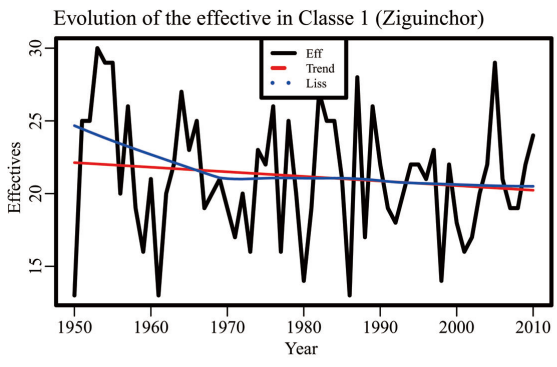

Evolution of the effective in Classe 3 (Ziguinchor)

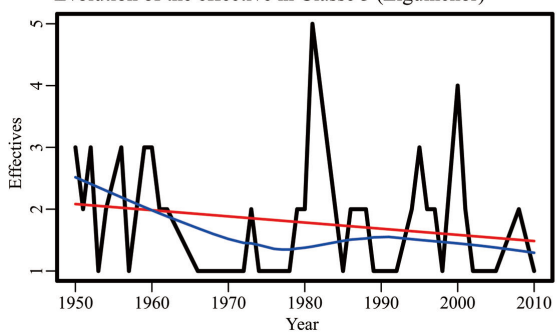

Evolution of the effective in Classe 2 (Ziguinchor)

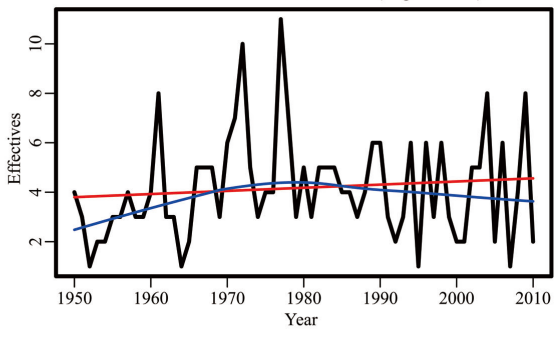

Evolution of the effective in Classe 4 (Ziguinchor)

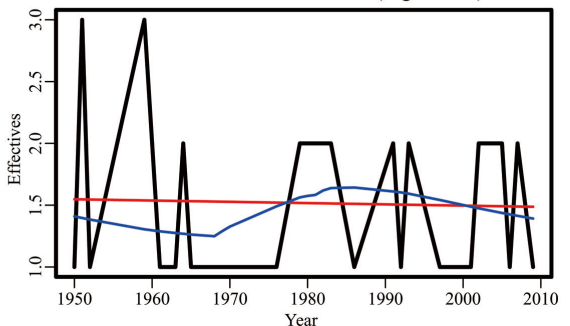

Figure 21. Interannual variability of the percentage of dry episodes in Ziguinchor.

class 1 - 4 days with more than 300 elements, followed by the Kaffrine region, and the Saint-Louis region in the north with the lowest number of dry episodes of these classes. The Ziguinchor and Kédougou regions have the lowest numbers of dry episodes in the 7-to-14-day class. From the class 16-18-day and above, the numbers of the different stations in this study are almost the same (Figure 22).

\subsection{Decadal Variability of the Different Classes of Dry Episodes}

Decadal analysis of dry episodes in the Dakar region shows that the decade 1951-1960 whose numbers remain well below average in almost all years (Figure 23 ) is the decade with the highest number of dry episodes in class 1 , followed by the decades 1961-1970, 2001-2010, 1981-1990, 1971-1980 and lastly 1991-2000. For the class 2, it is always the decade 1951-1960 that comes first (with the exception of the years 1953, 1958 and 1960, all the numbers in the other years are above the average for each year). This decade is followed by the decades 19711980, 1961-1970 and 1981-1990 (which have very similar numbers) and finally comes the decade 2001-2010. For class 3 it is again the first decade (1951-1960) that records the highest number of students, followed by 1981-1990, 1971-1980, 2001-2010, 1961-1970 and 1991-2000. Beyond class 3 the decadal variability is very irregular (Figure 23).

In Ziguinchor, the decadal analysis shows that the decade 1951-1960 records the largest number (about 300) of dry episodes of class 1 followed by the decades 1981-1990; 1961-1970; 2001-2010; 1971-1980 and 1991-1990 (whose numbers for this class are very similar). Then there is a rapid decrease (for all decades) in the number of dry episodes from class 1 to class 2, with the 1971-1980 decade coming first for class 2, followed by the decades 1981-1990; 2001-2010; 1991-2000 and 1951-1960 in last position (for all years the number of breaks is below average). The decade 1951-1960 comes first with regard to dry episodes in 

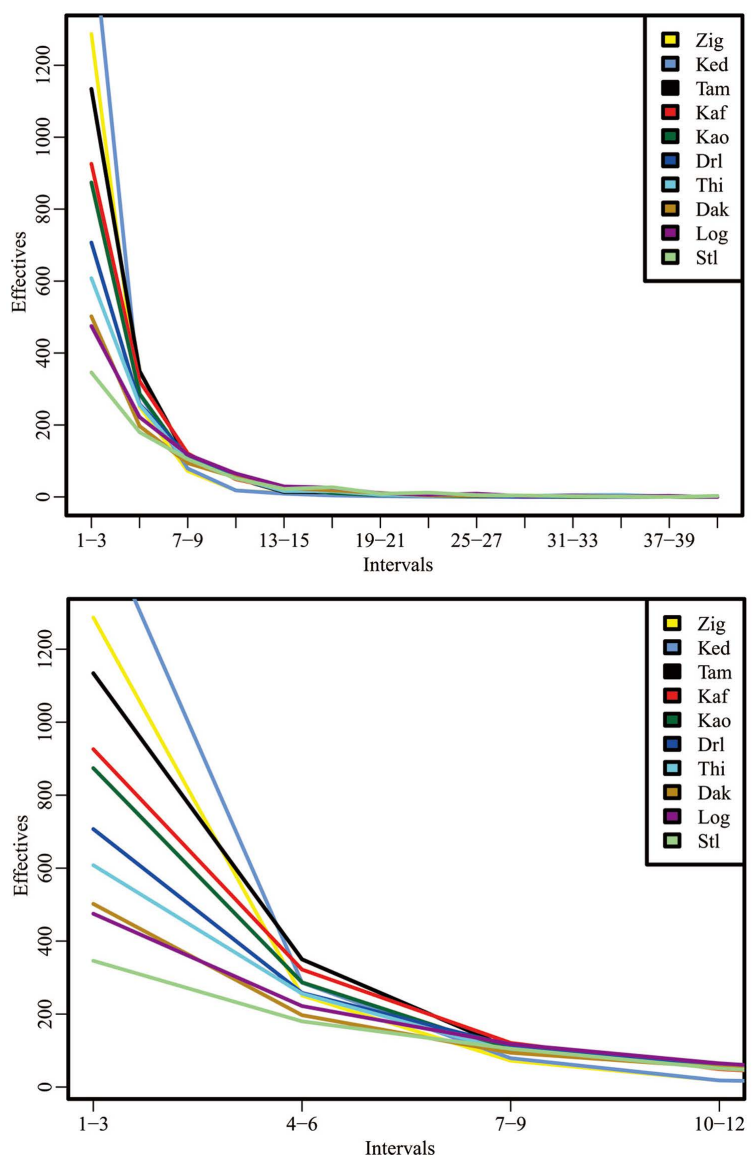

Figure 22. Comparison of the distributions of the different classes of dry sequence lengths between stations.

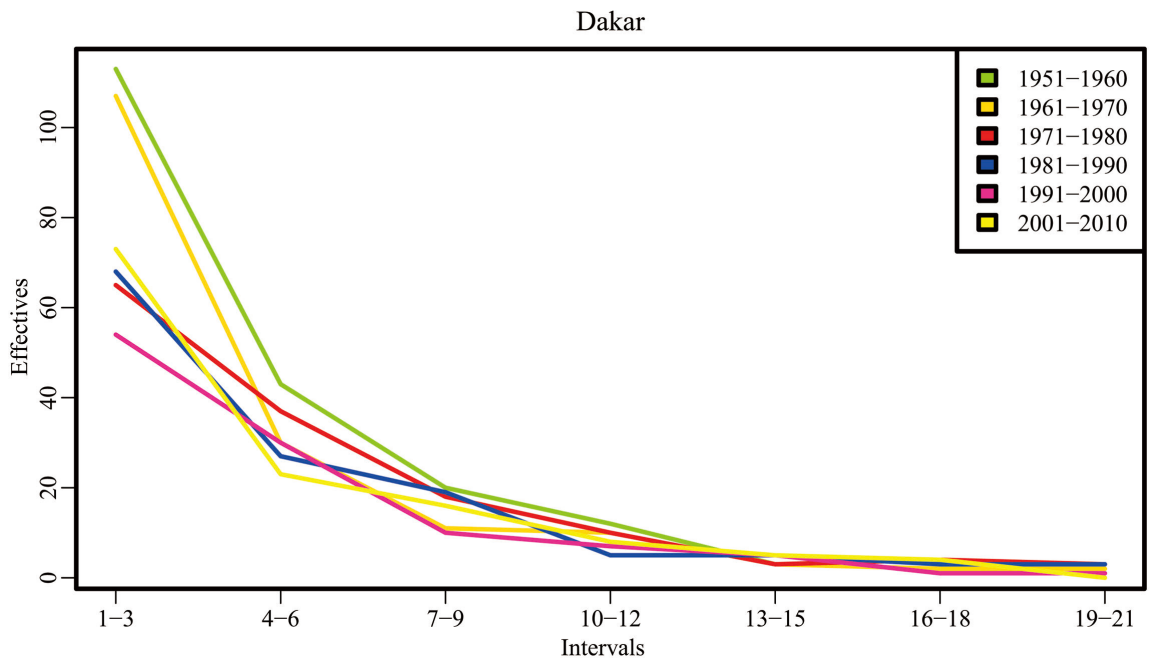

Figure 23. Decadal class sizes (a) and Anomalies of the different classes (b) in the DAKAR region from 1951-2010.

class 3 followed by the decades 1991-2000; 1971-1980; 1981-1990; 2001-2010 and 1961-1970, but beyond this class there is no significant variation between decades (Figure 24). 
In the Thiès region, it is the decade 1951-1960 that shows, according to class 1 , the largest number of dry episodes followed by 1961-1970; 1981-1990; 19912000; 2001-2010 and 1971-1980 periods (whose annual numbers are below average except for a few small years). The last two decades (1991-2000; 20012010) and the decade 1971-1980 have numbers very close to the dry episodes of class 2 but also have the largest numbers for breaks in this class, whose first decade has the smallest numbers. For the class 3 breaks, the 1971-1980 period has the smallest number. For other decades, the difference in their numbers is not significant enough and beyond that there is little decadal variability (Figure 25).

In the Diourbel region, the decadal variability of dry episodes shows that the period 1951-1960 is the most important for dry episodes of class 1, followed by the periods 1961-1970; 2001-2010; 1971-1980; 1981-1990 and 1991-2000 (the last

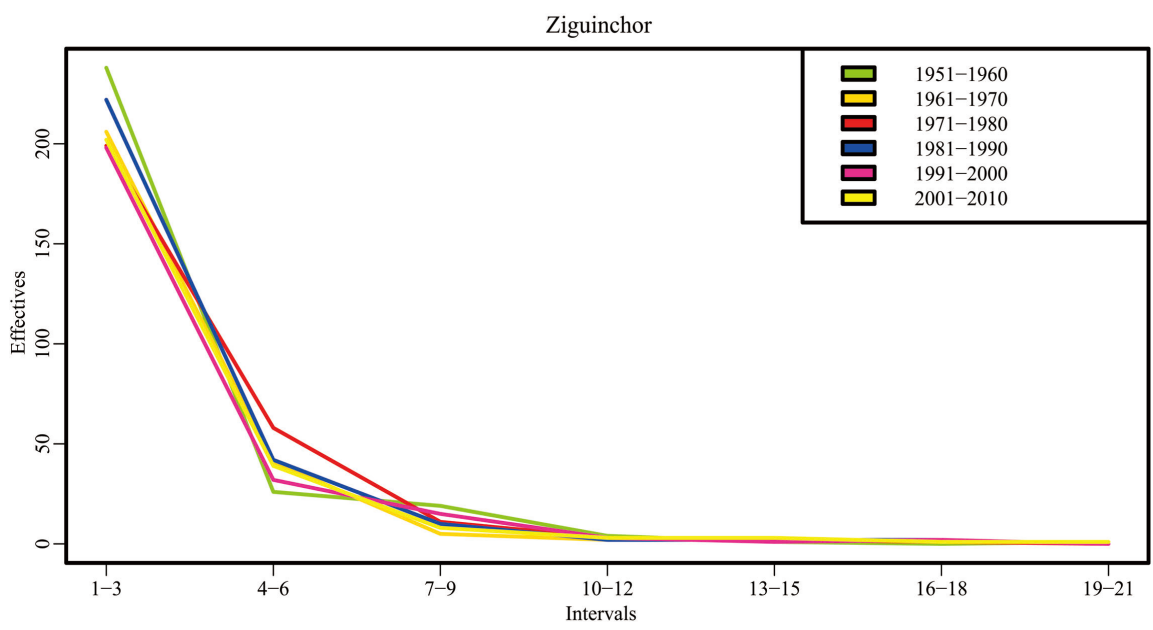

Figure 24. Decadal class sizes (a) and Anomalies of the different classes (b) in the Ziguinchor region from 1951-2010.

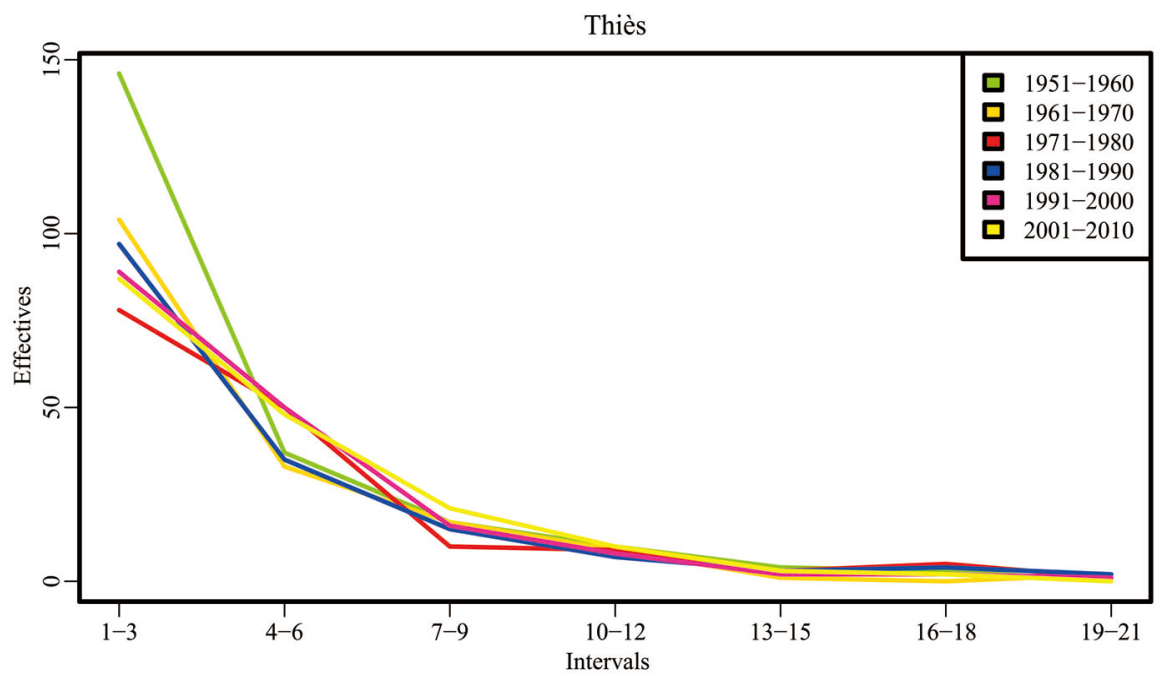

Figure 25. Decadal class sizes (a) and Anomalies of the different classes (b) in the Thiès region from 1951-2010. 
two decades have similar numbers). For class 2, it is the decade 2001-2010 that has the largest number of breaks, followed by the decades 1971-1980; 1991-2000; 1981-1990 and lastly 1951-1960. The decade 1971-1980 has the smallest number of breaks for class 3 and for the same class the decade 1981-1990 has the highest number of episodes followed by 2010-2010; 1961-1970; 1951-1960 and 1991-2000. It can be noted that beyond this class the decadal variability is very low (Figure 26).

In the Kaffrine region, it is the first decade of 1951-1960 that records the greatest number of rainfall breaks in class1 (over the whole decade the annual numbers are below average). For class1, the 1951-1960 decade is followed by the decades 1961-1970, 2001-2010, 1981-1990, 1971-1980 and 1991-2000 and for class 2 it is the decades 1961-1970, 1971-1980, 1981-1990, 1991-2000 which come successively in the lead followed by the period 2001-2010. It can be seen that from class 3 onwards the decennial numbers of dry episodes become closer and closer (Figure 27).

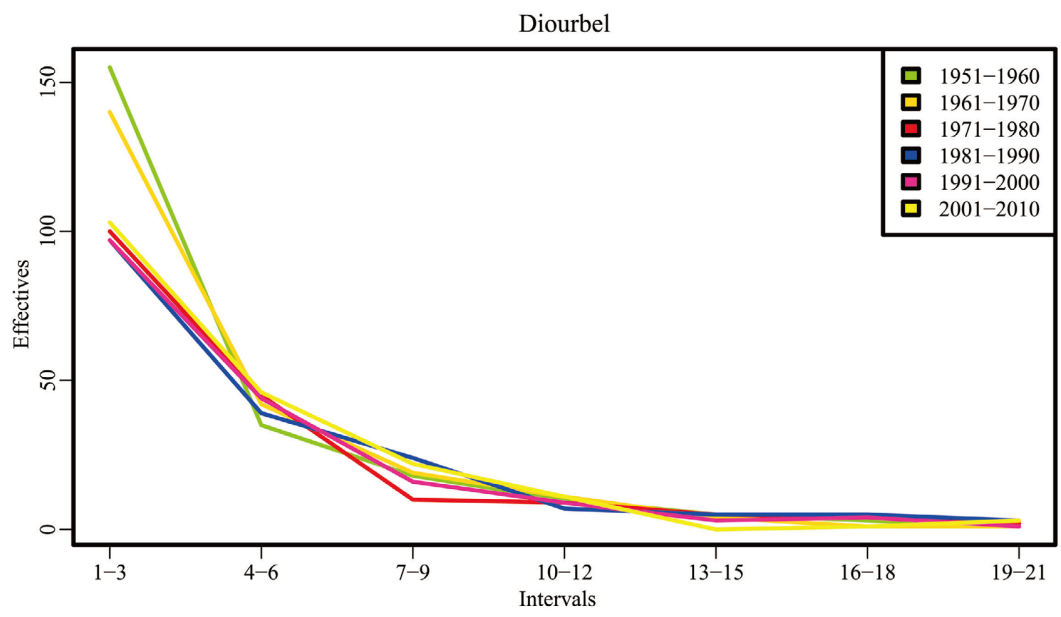

Figure 26. Decadal class sizes (a) and Anomalies of the different classes (b) in the Diourbel region from 1951-2010.

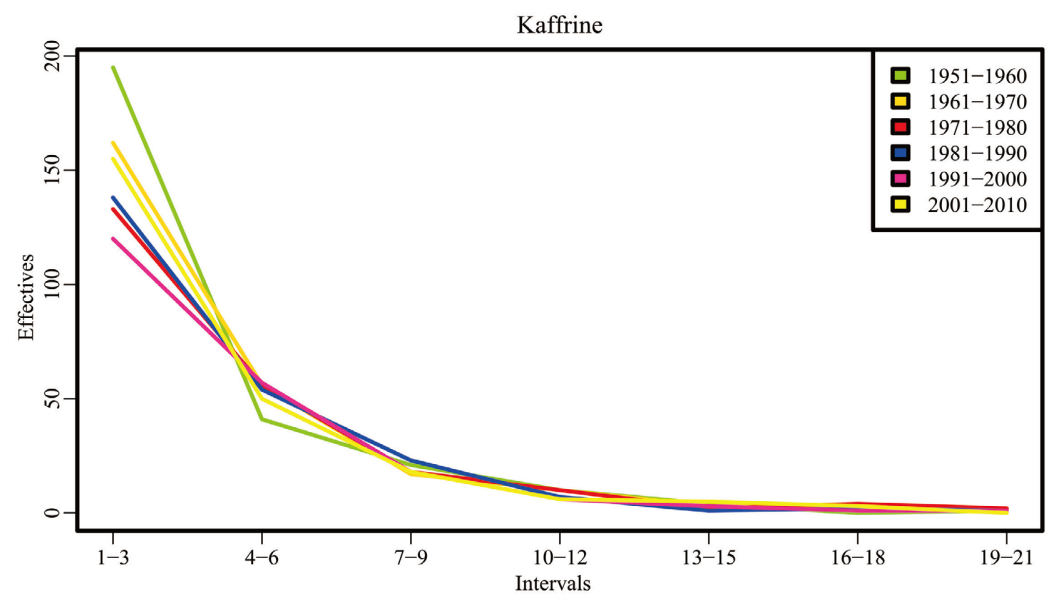

Figure 27. Decadal class sizes (a) and Anomalies of the different classes (b) in the Kaffrine region from 1951-2010. 
As for the Kaolack region, the period 1951-1960 shows the highest values in class 1, followed by 2001-2010; 1981-1990; 1971-1980 and finally 1991-2000. For the class 2, all decades record similar values except for the decade 1971-1980, which shows the lowest number of breaks for this class. One can note that, it is this same class that records the highest number of $10-12$ day class episodes (Figure 28).

In the Kedougou region, class 1 is the highest in terms of numbers during the decade 1961-1970, followed by 1951-1960, 2001-2010, and the other decades (1971-1980, 1981-1990 and 1991-2000) have the lowest numbers with very similar values. For class 2, with the exception of the decade 1991-2000, which is higher, all classes show more or less little different. It can be noted that from class 3 onwards the variability is very low (Figure 29).

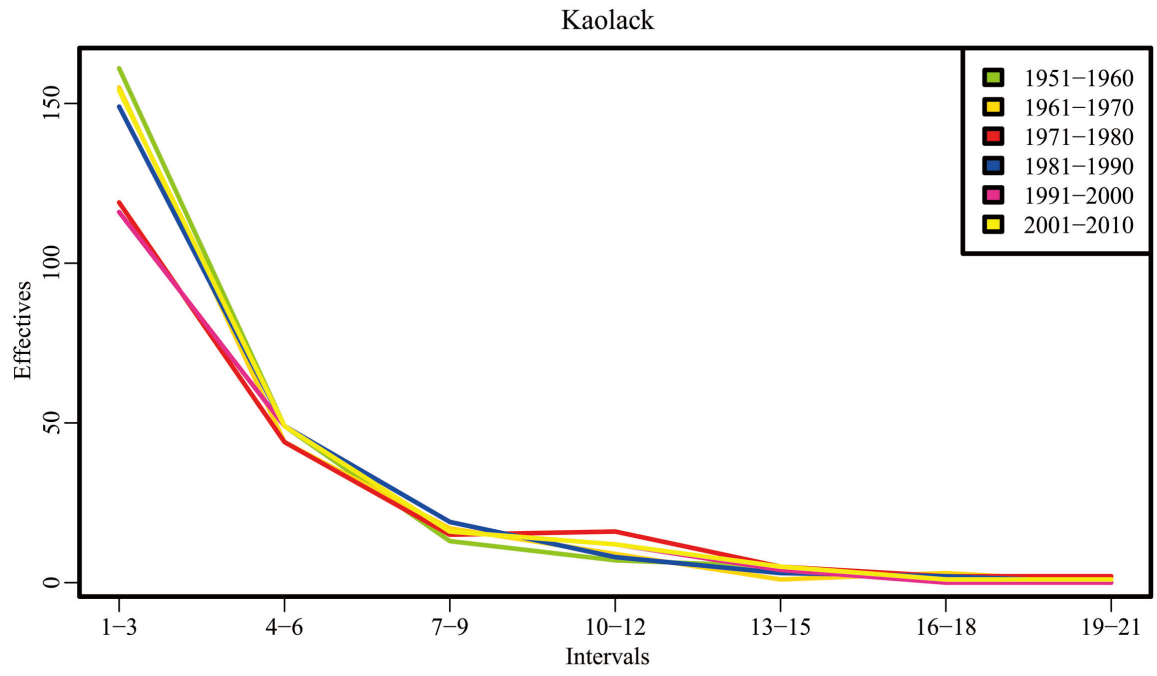

Figure 28. Decadal class sizes (a) and Anomalies of the different classes (b) in the Kaolack region from 1951-2010.

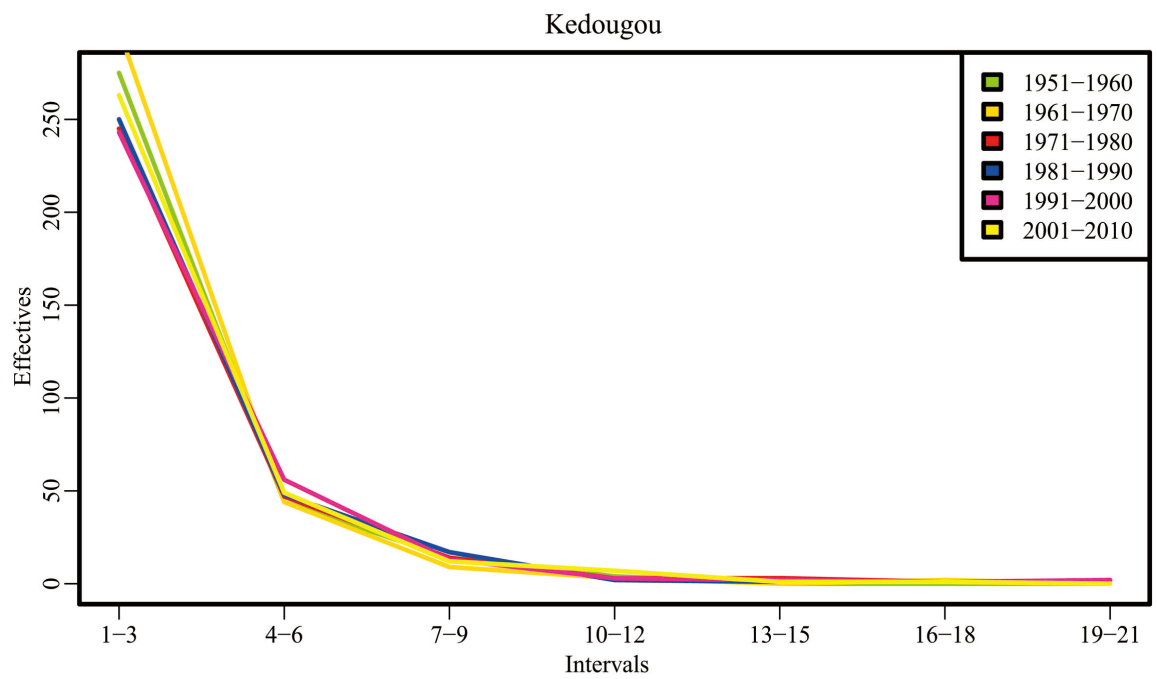

Figure 29. Decadal class sizes (a) and Anomalies of the different classes (b) in the Kedougou region from 1951-2010. 
In the Tamba region, it is always the first decade of the period (1950-2010) that shows high values for the class1, then come the decades 1961-1970; 1981-1990; 1971-1980; 2001-2010 and finally 1991-2000. For class 2 , it is the period 1971-1980 that records the greatest values, followed successively by the decades 1981-1990; 2001-2010; 1991-2000 and the two decades 1961-1970; 1951-1960 come in last place with very similar numbers. Then we have the numbers of the class 3 with the two decades 1991-2000 and 2000-2010 coming first, followed by the other decades of the period 1950-2010 which have almost the same numbers. It is particularly the decade 1991-2000 which has a rather different number of $10-12$ days than the other decades (Figure 30).

In the region of Louga, the decade 1951-1960 which has the greatest number of dry episodes of the class 1, followed by the decades 1961-197; 1981-1990; 2001-2010; 1991-2000 and finally 1971-1980. It is always the period 1950-1960 which shows higher values in terms of class 1 and class 2, followed by the periods 1991-2000; 2001-2010; 1961-1970; 1971-1980 and 1981-1990. For the class 3 , the two decades (2001-2010 and 1961-1970) show similar values followed by the decades 1951-1960; 1971-1980; 1981-1990 and 1991-2000 (Figure 31).

In the Saint-Louis region, apart from the first two decades (1951-1960 and 1961-1970) of the 1950-2010 period, which have a number of dry episodes in class 1 above the annual average, all other decades display values below their annual average. For class 2, the decade 1961-1970 is the highest, followed by the decades 1951-1960; 1991-2000; 2001-2010; 1981-1990 and finally 1971-1980. In contrast to the other stations, this region has a fairly high variability for the other classes of dry episodes (Figure 32).

\subsection{Correlation}

A correlation coefficient (R) calculates the extent to which two variables tend to change together. The coefficient describes the importance and direction of the

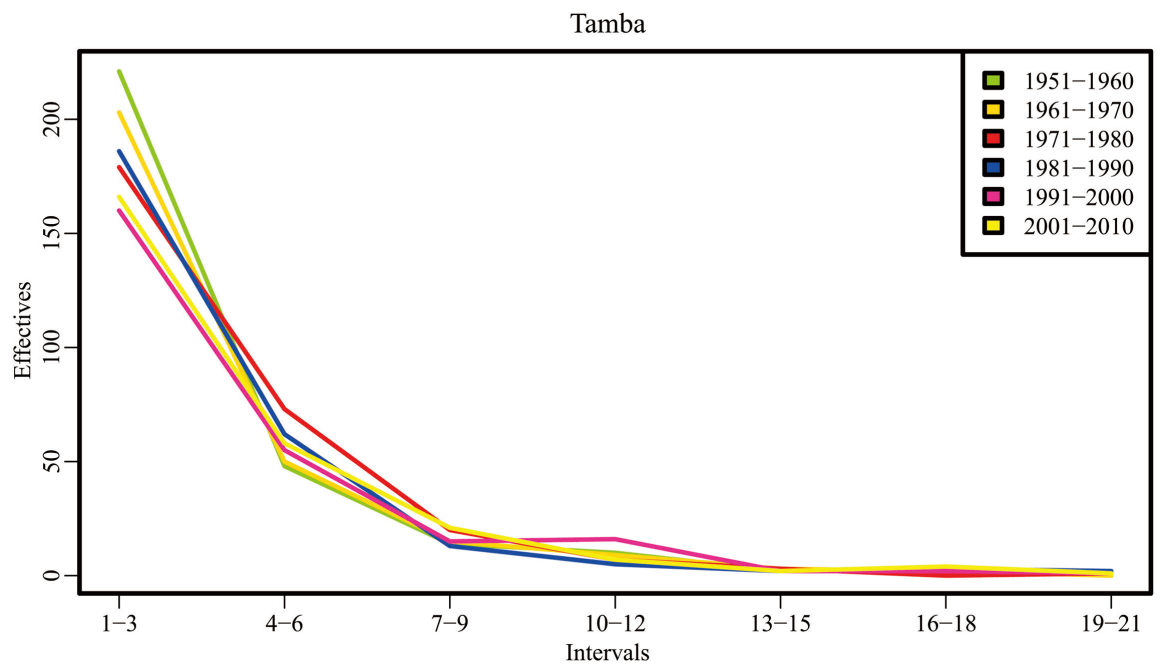

Figure 30. Decadal class sizes (a) and Anomalies of the different classes (b) in the Tambacounda region from 1951-2010. 


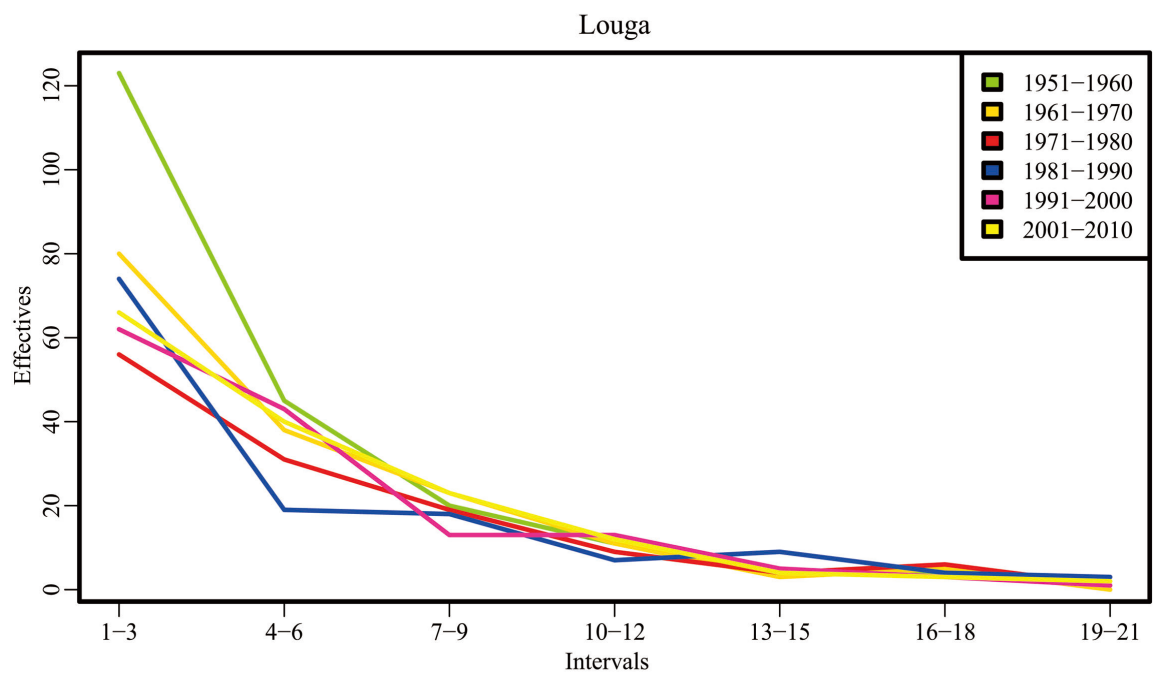

Figure 31. Decadal class sizes and Anomalies of the different classes (b) in the Louga region from 1951-2010.

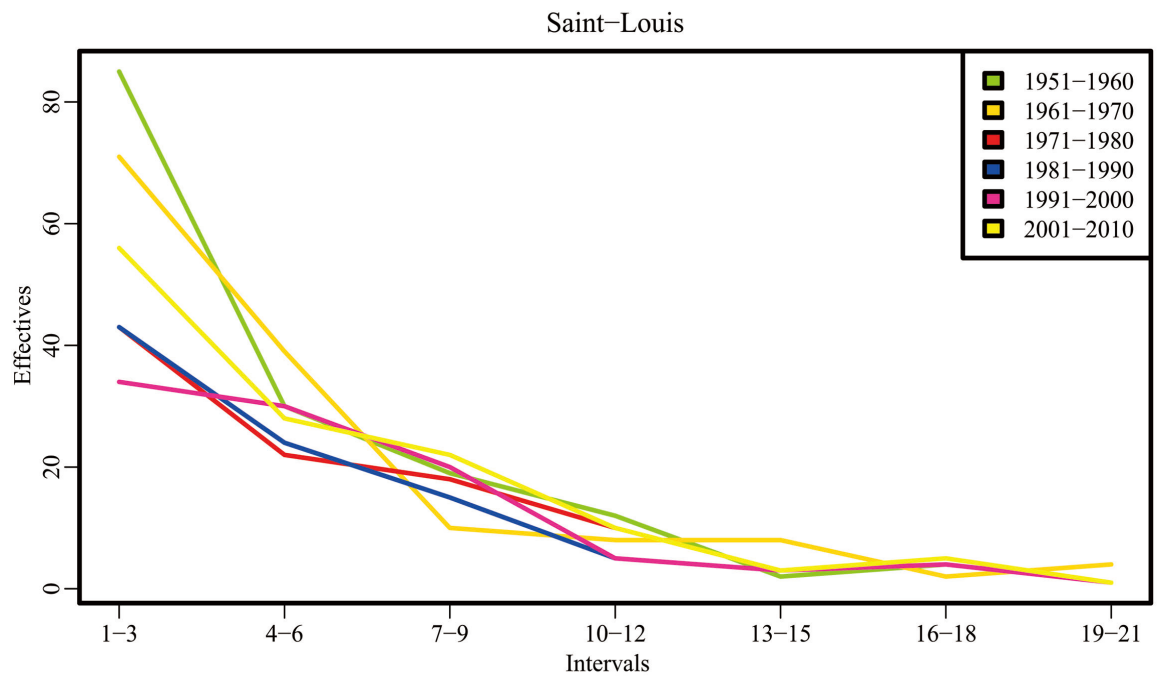

Figure 32. Decadal class sizes (a) and Anomalies of the different classes (b) in the SaintLouis region from 1951-2010.

relationship. In our study two methods (Pearson and Spearman) were used to calculate the correlation coefficients between the average length of breaks and maximum breaks on the one hand and between the annual rainfall and the annual total number of dry spells on the other hand. Indeed, Pearson's correlation evaluates the linear relationship between two continuous variables. A relationship is said to be linear when a change in one of the variables is associated with a proportional change in the other variable. Spearman's correlation evaluates the monotonic relationship between two continuous or ordinal variables. In a monotonic relationship, the variables tend to change together, but not necessarily at a constant rate. The $\mathrm{p}$-value coefficient ( $\mathrm{p}$ ) has also been determined to see if the correlation between the variables is significant by comparing the value of $p$ to the significance level. In general, a significance level (rated alpha or $\alpha$ ) of 0.05 
gives good results. A value of 0.05 in $\alpha$ indicates that the risk of concluding that a correlation exists when in reality there is no correlation is $5 \%$. The value of $\mathrm{p}$ indicates whether the correlation coefficient is significantly different from 0 (a null coefficient indicates that there is no linear relationship).

Value of $\mathrm{p} \leq \alpha$ : the correlation is statistically significant if the value of $\mathrm{p}$ is less than or equal to your significance level, you can conclude that the correlation is different from 0.

Value of $\mathrm{p}>\alpha$ : the correlation is not statistically significant if the value of $\mathrm{p}$ is greater than your significance level, you cannot conclude that the correlation is different from 0.

For the correlation between the mean duration of breaks and maximum breaks, both methods (Pearson and Spearman) show a strong linear but also monotonous relationship between the two series in all the regions studied. This is well confirmed by the p-values which are, at all times, lower than 0.05 . The correlation between the mean duration of breaks and the maximum breaks is also well confirmed by the p-values which are, at all times, lower than 0.05 (Table 1). The correlation between the mean duration of breaks and the maximum breaks is also well confirmed by the p-values. Concerning the correlation between cumulative rainfall and the annual number of breaks, it can be noted that with the exception of the regions of Ziguichor and Tamba where the coefficients of the former show moderate values between the two variables (cumulative rainfall and number of breaks) and those of the other show a very weak relationship between the two), all the coefficients of the other regions show an almost non-existent relationship between the two variables (Table 2).

The monthly evolution of dry episodes presents different situations according to classes of selected episodes. Indeed, the evolution of dry sequences of class 1 (1 - 3 days), which are the most important, increase until the middle of the rainy

Table 1. Correlation between average length days of dry spells and maximum dry spells. Significant correlations are in bold.

\begin{tabular}{ccccccccccccc}
\hline Methods & Coefficients & Ziguinchor & Diourbel & Kaffrine & Kaolack & Kedougou & Louga & Saint-Louis & Tamba & Thies & Dakar \\
\hline \multirow{2}{*}{ Pearson } & $\mathrm{R}$ & 0.73 & 0.70 & 0.74 & 0.61 & 0.68 & 0.61 & 0.71 & 0.66 & 0.69 & 0.84 \\
& P-value & $3 \times 10^{-11}$ & $3 \times 10^{-14}$ & $7 \times 10^{-12}$ & $10^{-7}$ & $2 \times 10^{-9}$ & $2 \times 10^{-7}$ & $10^{-10}$ & $9 \times 10^{-9}$ & $6 \times 10^{-10}$ & $2 \times 10^{-16}$ \\
& $\mathrm{R}$ & 0.79 & 0.69 & 0.79 & 0.68 & 0.64 & 0.76 & 0.69 & 0.72 & 0.72 & 0.76 \\
\multirow{2}{*}{ Spearman } & P-value & $5 \times 10^{-14}$ & $4 \times 10^{-10}$ & $4 \times 10^{-14}$ & $2 \times 10^{-9}$ & $10^{-8}$ & $10^{-12}$ & $9 \times 10^{-10}$ & $3 \times 10^{-11}$ & $7 \times 10^{-11}$ & $2 \times 10^{-12}$ \\
& & & & & & & & & & & &
\end{tabular}

Table 2. Correlation between the cumulative rainfall and the annual number of dry spells. Significant correlations are in bold.

\begin{tabular}{|c|c|c|c|c|c|c|c|c|c|c|c|}
\hline Methods & Coefficients & Ziguinchor & Diourbel & Kaffrine & Kaolack & Kedougou & Louga & Saint-Louis & Tamba & Thies & Dakar \\
\hline \multirow{2}{*}{ Pearson } & $\mathrm{R}$ & -0.53 & 0.02 & -0.05 & -0.21 & -0.04 & 0.01 & 0.15 & -0.46 & 0.04 & -0.06 \\
\hline & P-value & $3 \times 10^{-5}$ & 0.89 & 0.70 & 0.10 & 0.77 & 0.91 & 0.26 & $5 \times 10^{-4}$ & 0.77 & 0.65 \\
\hline \multirow{2}{*}{ Spearman } & $\mathrm{R}$ & -0.49 & -0.07 & -0.08 & -0.23 & -0.09 & -0.04 & 0.16 & -0.05 & -0.04 & -0.07 \\
\hline & $\mathrm{P}$-value & $4 \times 10^{-5}$ & 0.60 & 0.52 & 0.06 & 0.48 & 0.76 & 0.21 & $2 \times 10^{-3}$ & 0.75 & 0.57 \\
\hline
\end{tabular}


B. Ndiaye et al.

Table 3. Frequency of occurrence of dry sequences as a function of months for each station (1950-2010).

\begin{tabular}{|c|c|c|c|c|c|}
\hline Regions & Months & 1 - 3 Days & 4 - 6 Days & 7 - 9 Days & >9 Days \\
\hline \multirow{5}{*}{ Ziguinchor } & June & 149 & 75 & 31 & 22 \\
\hline & July & 304 & 46 & 11 & 4 \\
\hline & August & 297 & 24 & 4 & 1 \\
\hline & September & 288 & 41 & 4 & 1 \\
\hline & October & 148 & 50 & 16 & 13 \\
\hline \multirow{5}{*}{ Dakar } & June & 11 & 7 & 2 & 9 \\
\hline & July & 46 & 13 & 7 & 23 \\
\hline & August & 85 & 27 & 15 & 8 \\
\hline & September & 72 & 27 & 13 & 3 \\
\hline & October & 20 & 8 & 5 & 14 \\
\hline \multirow{5}{*}{ Kaffrine } & June & 65 & 38 & 17 & 28 \\
\hline & July & 166 & 72 & 25 & 18 \\
\hline & August & 229 & 59 & 17 & 8 \\
\hline & September & 213 & 56 & 16 & 2 \\
\hline & October & 70 & 33 & 183 & 2 \\
\hline \multirow{5}{*}{ Tamba } & June & 147 & 70 & 26 & 41 \\
\hline & July & 258 & 88 & 28 & 10 \\
\hline & August & 324 & 70 & 12 & 9 \\
\hline & September & 285 & 60 & 12 & 9 \\
\hline & October & 87 & 48 & 22 & 28 \\
\hline \multirow{5}{*}{ Saint-Louis } & June & 7 & 5 & 4 & 4 \\
\hline & July & 31 & 13 & 7 & 22 \\
\hline & August & 67 & 26 & 17 & 16 \\
\hline & September & 49 & 26 & 17 & 11 \\
\hline & October & 8 & 8 & 4 & 15 \\
\hline \multirow{5}{*}{ Kedougou } & June & 276 & 91 & 25 & 16 \\
\hline & July & 405 & 62 & 13 & 0 \\
\hline & August & 397 & 41 & 6 & 0 \\
\hline & September & 358 & 47 & 6 & 4 \\
\hline & October & 154 & 45 & 29 & 15 \\
\hline \multirow{5}{*}{ Thies } & June & 14 & 6 & 4 & 16 \\
\hline & July & 59 & 28 & 14 & 26 \\
\hline & August & 115 & 34 & 15 & 13 \\
\hline & September & 94 & 47 & 8 & 6 \\
\hline & October & 37 & 12 & 13 & 7 \\
\hline
\end{tabular}




\begin{tabular}{|c|c|c|c|c|c|}
\hline & June & 57 & 38 & 14 & 29 \\
\hline & July & 161 & 50 & 19 & 24 \\
\hline \multirow[t]{5}{*}{ Kaolack } & August & 217 & 60 & 11 & 11 \\
\hline & September & 194 & 44 & 13 & 7 \\
\hline & October & 61 & 27 & 14 & 14 \\
\hline & June & 27 & 15 & 13 & 22 \\
\hline & July & 102 & 42 & 20 & 27 \\
\hline \multirow[t]{5}{*}{ Dourbel } & August & 150 & 41 & 15 & 12 \\
\hline & September & 132 & 50 & 10 & 9 \\
\hline & October & 31 & 12 & 15 & 18 \\
\hline & June & 8 & 6 & 4 & 16 \\
\hline & July & 43 & 25 & 12 & 28 \\
\hline \multirow[t]{3}{*}{ Louga } & August & 94 & 37 & 23 & 14 \\
\hline & September & 82 & 41 & 19 & 7 \\
\hline & October & 27 & 12 & 8 & 15 \\
\hline
\end{tabular}

season (August-September) and then decrease rapidly from October onwards. For all the regions studied, the dry episodes of this class reach their maximum in August (Table 3). Dry episodes of class 2 (4 - 6 days) are most common at the beginning (June) and end (October) of the season, but are infrequent in August and September in the Ziguinchor and Kédougou regions, while in regions such as Dakar, Thiès, Saint-Louis and Louga, the number of dry episodes in this class is low in June and October. For dry episodes of class 4 ( $>9$ days), their numbers are very low or non-existent in some regions in August and September, except in Louga and Saint-Louis. These developments reflect the importance of convective systems, which provide most of the rainfall in the Sahel in general, and whose activity is most intense in August-September (Sagna et al., 2016).

\section{Conclusion and Perspectives}

We have used timeseries of precipitation data for many stations of Senegal to study the spatio-temporal variability of rainfall breaks. These data, extracted from the CERAAS database, cover the period 1950-2010 and represent an enough long series to allow such study. To do this, we have defined the rainfall breaks in terms of days regrouped in classes, going from class 1 to class 4 for rainfall breaks of 1 - 3 days; 4 - 6 days; 7 - 9 days and those greater than 9 days respectively.

Our results show that in the southern regions of Senegal (Zigunchor; Tamba; Kedougou; Kolda; Vélingara) class 1 is much more frequent. This is mainly due to the fact that ITCZ is present almost throughout the rainy season. Class 4 shows practically very low values, which means breaks longer than 9 days are in- 
frequent. For the Center (Diourbel, Kaolack, Fatick), we note all the classes but with a slight predominance of class 2 and class 3. In addition, we note that in this area, class 2 is more frequent in June. As for the North region (Saint-Louis), classes 3 and 4 are much more frequent. This spatial variability of rainfall breaks is clearly associated with the rainfall gradient between the North and the South. The temporal evolution of the numbers of each class intrinsically follows the evolution of the ITCZ.

This study on the spatio-temporal distribution of rainfall breaks is a step forward in understanding the installation and development of the rainy season in Senegal. The results show that the number of dry days of the class 1 ( 1 - 3 days) decreases from south to north as opposed to maximum breaks which increase from south to north. The practical interest of having a calendar of the rainfall break intensification phases is that it can serve as a basis for long-term planning of activities sensitive to intra-seasonal rainfall variability. In the agriculture sector, break periods can be seen as periods when the risk of the dreaded dry sequence occurrence at critical crop phases (maize flowering, sorghum ripening) is higher. The results of our study offer interesting research perspectives to be developed in the near future. These are organized around the following main axes:

- Extend the study until 2018 to take into account the recent variations in rainfall breaks.

- To make medium-term forecasts of the occurrence of breaks and to make projections.

- Evaluate the impact of dry episodes on aggressive vector densities via their consequences on the water height of larval sites.

- The demonstration of possible correlations between dry episodes and the recrudescence of dangerous meteorological phenomena for several domains would be of great practical use for the planning of the activities of companies in charge of the management of the safety of air navigation and air carriers, but also for agriculture.

\section{Conflicts of Interest}

The authors declare no conflicts of interest regarding the publication of this paper.

\section{References}

ANSD (2019). https://satisfaction.ansd.sn/

Barron, J. A., Heusser, L. E., Herbert, T. D., Timothy, D., \& Lyle, M. W. (2003). HighResolution Sedimentological and Paleontological Record of ODP Site 1671019. PANGAEA. https://doi.org/10.1594/PANGAEA.841955

Benzerti, Z., \& Habaieb, H. (2001). Étude de la persistance de la secheresse en Tunisie par utilisation des chaînes de Markov (1909-1996). Secheresse, 12, 215-220.

Bichet, A., \& Diedhiou, A. (2018). Less Frequent and More Intense Rainfall along the Coast of the Gulf of Guinea in West and Central Africa (1981-2014). Climate Research, 76, 191-201. https://doi.org/10.3354/cr01537 
Fodé, M., \& Adamou, O. M. (1996). Analyse des séquences sèches au Niger de 1950 à 1991. In G. Bernard (Ed.), Problèmes de validation des méthodes d'estimation des précipitations par satellite en Afrique intertropicale (pp. 189-224). ORSTOM.

Garcia, C. C., \& Martin-Vide, J. (1993). Analyse par la chaîne de Markov de la sécheresse dans le sud-est de l'Espagne. Science et Changements Planétaires/Sécheresse, 4, 123-129.

IPCC (2016). Climate Change and Land: An IPCC Special Report on Climate Change, Desertification, Land Degradation, Sustainable Land Management, Food Security, and Greenhouse Gas Fluxes in Terrestrial Ecosystems [P. R. Shukla, J. Skea, E. Calvo Buendia, V. Masson-Delmotte, H.-O. Pörtner, D. C. Roberts, P. Zhai, R. Slade, S. Connors, R. van Diemen, M. Ferrat, E. Haughey, S. Luz, S. Neogi, M. Pathak, J. Petzold, J. Portugal Pereira, P. Vyas, E. Huntley, K. Kissick, M. Belkacemi, \& J. Malley (Eds.)]. In Press.

IPCC (2019). IPCC Special Report on Climate Change, Desertification, Land Degradation, Sustainable Land Management, Food Security, and Greenhouse gas fluxes in Terrestrial Ecosystems. https://www.ipcc.ch/report/srccl/

Lebel, T., Parker, D. J., Flamant, C., Bourlès, B., Marticorena, B., Mougin, E., Peugeot, C., Diedhiou, A., Haywood, J. M., Ngamini, J. B., Polcher, J., Redelsperger, J.-L., \& Thorncroft, C. D. (2010). The AMMA Field Campaigns: Multiscale and Multidisciplinary Observations in the West African Region. Quarterly Journal of the Royal Meteorological Society, 136, 8-33. https://doi.org/10.1002/qj.486

Moron, V., Robertson, A. W., \& Ward, M. N. (2006). Seasonal Predictability and Spatial Coherence of Rainfall Characteristics in the Tropical Setting of Senegal. Monthly Weather Review, 134, 3248-3262. https://doi.org/10.1175/MWR3252.1

Porkka, M. et al. (2021). Is Wetter Better? Exploring Agriculturally-Relevant Rainfall Characteristics over Four Decades in the Sahel. Environmental Research Letters, 16, Article ID: 035002. https://doi.org/10.1088/1748-9326/abdd57

Redelsperger, J. L., Thorncroft, C. D., Diedhiou, A., Lebel, T., Parker, D. J., \& Polcher, J. (2006). African Monsoon Multidisciplinary Analysis: An International Research Project and Field Campaign. Bulletin of the American Meteorological Society, 87, 1739-1746. https://doi.org/10.1175/BAMS-87-12-1739

Sagna, P., Ndiaye, O., Diop, C., Niang, A. D., \& Sambou, P. C. (2016). Les variations recentes du climat constatees au Senegal sontelles en phase avec les descriptions donnees par les scenarios du GIEC? Pollution-Atmospherique, Climat, Sante, Societe, 227.

Salack, S., Muller, B., Gaye, T. A., Hourdin, F., \& Cissé, N. (2012). Analyses multi-échelles des pauses pluviométriques au Niger et au Sénégal. Sécheresse, 23, 3-13.

Sané, T. (2003). La variabilité climatique et ses conséquences sur l'environnement et les activités humaines en Haute-Casamance (Sud Sénégal). Thèse de 3ème cycle, Université Cheikh Anta Diop, 370 p.

Sané, T., Diop, M., \& Sagna, P. (2008). Étude de la qualité de la saison pluvieuse en Haute-Casamance (Sud Sénégal). Science et Changements Planétaires/Sécheresse, 19, 23-28.

Segele, Z., \& Lamb, P. (2005). Characterization and Variability of Kiremt Rainy Season over Ethiopia. Meteorology and Atmospheric Physics, 89, 153-180. https://doi.org/10.1007/s00703-005-0127-x

Sivakumar, M. V. K. (1992). Empirical Analysis of Dry Spells for Agricultural Applications in West Africa. Journal of Climate, 5, 532-539. https://doi.org/10.1175/1520-0442(1992)005<0532:EAODSF>2.0.CO;2

Sultan, B., Lalou, R., Sanni, M. A. et al. (2011). Les Sociétés Rurales face aux changements 
B. Ndiaye et al.

climatiques et environmentaux en Afrique de l'Ouest.

https://www.locean-ipsl.upmc.fr/ ESCAPE/

Wilhite, D. A., \& Glantz, M. H. (1985). Understanding the Drought Phenomenon: The Role of Definitions. Water International, 10, 111-120.

https://doi.org/10.1080/02508068508686328 